IZA DP No. 380

\title{
A Kaldor Matching Model of Real Wage Declines
}

Michael Sattinger

October 2001 


\title{
A Kaldor Matching Model of Real Wage Declines
}

\author{
Michael Sattinger \\ Department of Economics, State University of New York at Albany
}

Discussion Paper No. 380
October 2001

\author{
IZA \\ P.O. Box 7240 \\ D-53072 Bonn \\ Germany \\ Tel.: +49-228-3894-0 \\ Fax: +49-228-3894-210 \\ Email: iza@iza.org
}

This Discussion Paper is issued within the framework of IZA's research area General Labor Economics. Any opinions expressed here are those of the author(s) and not those of the institute. Research disseminated by IZA may include views on policy, but the institute itself takes no institutional policy positions.

The Institute for the Study of Labor (IZA) in Bonn is a local and virtual international research center and a place of communication between science, politics and business. IZA is an independent, nonprofit limited liability company (Gesellschaft mit beschränkter Haftung) supported by the Deutsche Post AG. The center is associated with the University of Bonn and offers a stimulating research environment through its research networks, research support, and visitors and doctoral programs. IZA engages in (i) original and internationally competitive research in all fields of labor economics, (ii) development of policy concepts, and (iii) dissemination of research results and concepts to the interested public. The current research program deals with (1) mobility and flexibility of labor markets, (2) internationalization of labor markets and European integration, (3) the welfare state and labor markets, (4) labor markets in transition, (5) the future of work, (6) project evaluation and (7) general labor economics.

IZA Discussion Papers often represent preliminary work and are circulated to encourage discussion. Citation of such a paper should account for its provisional character. 
IZA Discussion Paper No. 380

October 2001

\section{ABSTRACT}

\section{A Kaldor Matching Model of Real Wage Declines*}

A model linking macroeconomic phenomena and income distribution in balanced growth equilibria is developed as a variant to the Kaldor model of factor shares. It departs from the original Kaldor model in assuming equal savings rates and production determined by a matching process between workers and jobs. Macroeconomic equilibrium (national savings equal to investment) determines the ratio of jobs to employment and the ratio of unemployed to vacancies. Competitive microeconomic behavior then determines the wage and interest rates. Changes in the ratio of national debt to employment have real effects on factor prices. Implications for effects of taxes and unemployment benefits are derived. The model explains recent declines in real wages relative to productivity.

JEL Classification: D33, E1, H2, J31

Keywords: Kaldor, real wage, interest rate, national debt, unemployment benefits, efficient taxation, matching, factor prices

Michael Sattinger

Department of Economics

State University of New York at Albany

Albany, NY 12222

USA

Tel.: +1518 442-4761

Fax: +1 518 442-4736

Email: m.sattinger@albany.edu

\footnotetext{
* The author is indebted to the Institute for the Study of Labor (IZA, Bonn) for support while this paper was written. Errors and opinions are the responsibility of the author.
} 


\section{Introduction}

The U.S. economy in recent decades has exhibited a substantial decline in the real wage relative to productivity and large changes in the real interest rate over long periods. This paper develops a model linking macroeconomic variables to factor prices and income distribution. Macroeconomic equilibrium (Aggregate Demand equal to Aggregate Supply) determines a ratio of jobs to employment, which (in combination with balanced growth labor flow conditions) determines the ratio of unemployed to vacancies. Given the ratio of unemployed to vacancies, labor decisions between working as employees or as entrepreneurs and competitive entrepreneur wage setting determine the wage rate and the interest rate.

The model developed is a variant of Nicholas Kaldor's Keynesian model of income distribution (1955-1956), in which equality between savings and investment in full employment balanced growth is brought about by shifts between profits and labor income instead of by fluctuations in economic activity. ${ }^{1}$ In Kaldor's approach, income distribution is partly explained by macroeconomic phenomena, and shifts of factor incomes are necessary to bring about macroeconomic equilibrium. The model developed here shares with Kaldor's model the involvement of income distribution with macroeconomics and the simultaneous explanation of both distributional and macroeconomic phenomena. Like Kaldor's model, it begins with the determination of a central variable by macroeconomic equilibrium, followed by microeconomic determination of factor prices. However, the mechanism linking macroeconomic equilibrium and income distribution is different. In Kaldor's model, full employment is assumed and an aggregate investment rate is determined exogenously by balanced growth parameters. Assuming a greater savings rate out of profits, income shifts between profits and labor income are brought about by changes in prices relative to wage rates until the savings rate equals the required investment rate. In contrast, in the model developed here, the level of production is determined endogenously, and the savings rate is assumed to be the same for all sources of income. All variables are real, so there is no inflation to bring about changes in the wage rate relative to the price level. In Kaldor's model, there is a fixed capital to production ratio so that marginal products of factors are not defined and do not determine factor prices. In the model developed here, there is a fixed proportions production function for output from one worker combined with one job, but at the aggregate level marginal contributions to production from an additional worker, an additional employer, or additional

\footnotetext{
${ }^{1}$ See discussions of Kaldor's model in Bertola (2000, pp. 400-498), Ferguson (1969, pp. 314322), Pasinetti (1962, 1974, p. 99), Rothschild (1993, Chapters 17-19), Skott (1989), Sattinger (2001, pp. liii-liv) and Tobin (1989). Kaldor's model is one of several approaches that involve income distribution in a macroeconomic model (see Bertola, 2000, Sattinger, 1990, and Weintraub, 1958).
} 
capital are defined. Then competitive market forces determine the real wage and real interest rate.

Table 1 shows interest rate, wage, productivity and debt variables that are relevant in this paper. The data are for the period 1961 to 1999. The real interest rate in column 2 is measured by the average interest rate on U.S. Treasury bonds with maturity over ten years minus inflation as measured by increases in the yearly average Consumer Price Index (CPI-U). The real wage is measured by average hourly earnings in 1982 dollars for total private employment, not seasonally adjusted. Productivity is measured by the Major Sector Multifactor Productivity Index for manufacturing. Column 5 is the real wage from column 3 divided by the multifactor productivity in column 4 . Column 6 shows the ratio of national debt to output, measured by the Congressional Budget Office as the ratio of national debt held by the public to Gross Domestic Product. There are alternative ways of measuring these variables, but the major patterns are unlikely to be affected.

The data show substantial changes in factor prices over long periods of time, with no indication that they are returning to an earlier equilibrium level. The real interest rate lies between two and three percent in the first half of the 1960's, falls below one percent (and often goes negative) from 1973 to 1980, rises to between five to eight percent between 1982 and 1987, and falls back to a range of three to five percent from $1988 \mathrm{on}$. As the real interest rate falls, the real wage rises from below seven in 1961 to levels above eight from 1970 to 1979. Then as the real interest rate rises from below one percent to a 17 year period above 3 percent, the real wage falls to a level below 8 . These changes are not part of business cycle stories describing fluctuations around a long run equilibrium. The long run changes in the real interest rate and wage rate could potentially be explained by the episode of inflation in the 1960's and 1970's but only by abandoning views that the effects of inflation on factor prices end less than a decade after stabilization of monetary growth. Productivity also does not explain the long run and substantial changes. Increases in productivity should raise both the real interest rate and the real wage. However, the real wage declines relative to multifactor productivity, as shown in the ratio in Column 5, from 1978 on. Use of output per hour instead of multifactor productivity would result in even steeper declines in the ratio of wages to productivity. Imperfections in the measurement of productivity cannot be the explanation for the observed long run behavior of factor prices since real interest rates and real wages move in opposite directions. Other explanations are possible (e.g., capital-skill complementarity) and cannot be ruled out by these data. This paper proposes an explanation based on the link between the macroeconomic sector and microeconomic determination of factor prices.

The stylized facts concerning long run relationships to be addressed by the model developed here are as follows. Over the period 1961 to 1999, the real 
interest rate declines, increases substantially and then declines to a level greater than the start of the period. The real wage relative to productivity is roughly inversely related to the real interest rate, rising and then declining. These patterns occur contemporaneously with a decline in the ratio of national debt to output from 1961 to the 1970's, followed by increases. While the effect of budget deficits on the interest rate are well known, this paper focuses on the ratio of national debt to output in balanced growth and its effects on both the real interest rate and the real wage rate. In the model that will be developed, balanced growth of a greater national debt absorbs more savings, reduces the ratio of jobs to employment and raises the ratio of unemployed to vacancies, which then reduces the real wage rate and raises the real interest rate. 


\section{Table 1: Factor Prices and Debt}

\begin{tabular}{|c|c|c|c|c|c|}
\hline 1 & 2 & 3 & 4 & 5 & 6 \\
\hline Year & Real Interest Rate & Real Wage & Productivity & Wage/Productivity & Debt/Output \\
\hline 1961 & 2.90 & 6.88 & 68.9 & .999 & 44.9 \\
\hline 1962 & 2.95 & 7.07 & 71.6 & .987 & 43.6 \\
\hline 1963 & 2.70 & 7.17 & 73.6 & .974 & 42.3 \\
\hline 1964 & 2.85 & 7.33 & 75.7 & .968 & 40.0 \\
\hline 1965 & 2.61 & 7.52 & 77.7 & .968 & 37.9 \\
\hline 1966 & 1.75 & 7.62 & 78.0 & .977 & 34.8 \\
\hline 1967 & 1.75 & 7.72 & 77.5 & .996 & 32.8 \\
\hline 1968 & 1.06 & 7.89 & 79.9 & .987 & 33.3 \\
\hline 1969 & 0.62 & 7.98 & 80.5 & .991 & 29.3 \\
\hline 1970 & 0.88 & 8.03 & 79.2 & 1.014 & 27.9 \\
\hline 1971 & 1.34 & 8.21 & 81.4 & 1.009 & 28.0 \\
\hline 1972 & 2.43 & 8.53 & 84.4 & 1.011 & 27.4 \\
\hline 1973 & 0.10 & 8.55 & 85.9 & .995 & 26.0 \\
\hline 1974 & -4.02 & 8.28 & 81.3 & 1.018 & 23.8 \\
\hline 1975 & -2.12 & 8.12 & 78.9 & 1.029 & 25.3 \\
\hline 1976 & 0.98 & 8.24 & 81.7 & 1.009 & 27.5 \\
\hline 1977 & 0.56 & 8.36 & 82.9 & 1.008 & 27.8 \\
\hline 1978 & 0.29 & 8.40 & 83.6 & 1.005 & 27.4 \\
\hline 1979 & -2.56 & 8.17 & 82.7 & .988 & 25.6 \\
\hline 1980 & -2.69 & 7.78 & 81.3 & .957 & 26.1 \\
\hline 1981 & 2.59 & 7.69 & 81.9 & .939 & 25.8 \\
\hline 1982 & 6.03 & 7.68 & 83.3 & .922 & 28.6 \\
\hline 1983 & 7.64 & 7.79 & 85.2 & .914 & 33.0 \\
\hline 1984 & 7.69 & 7.80 & 87.8 & .888 & 34.0 \\
\hline 1985 & 7.15 & 7.77 & 89.2 & .871 & 36.4 \\
\hline 1986 & 6.24 & 7.81 & 90.7 & .861 & 39.6 \\
\hline 1987 & 5.03 & 7.73 & 93.5 & .827 & 40.6 \\
\hline 1988 & 4.88 & 7.69 & 95.2 & .808 & 40.9 \\
\hline 1989 & 3.79 & 7.64 & 93.4 & .818 & 40.5 \\
\hline 1990 & 3.33 & 7.52 & 93.3 & .806 & 42.0 \\
\hline 1991 & 3.96 & 7.45 & 92.4 & .806 & 45.4 \\
\hline 1992 & 4.52 & 7.41 & 94.0 & .788 & 48.2 \\
\hline 1993 & 3.46 & 7.39 & 94.9 & .779 & 49.5 \\
\hline 1994 & 4.81 & 7.40 & 97.3 & .761 & 49.4 \\
\hline 1995 & 4.14 & 7.39 & 99.2 & .745 & 49.2 \\
\hline 1996 & 3.80 & 7.43 & 100.0 & .743 & 48.5 \\
\hline 1997 & 4.37 & 7.55 & 103.5 & .729 & 46.0 \\
\hline 1998 & 4.09 & 7.75 & 106.3 & .729 & 42.9 \\
\hline 1999 & 3.93 & 7.86 & 109.4 & .718 & 39.7 \\
\hline
\end{tabular}


The outline of the paper is as follows. All variables in the model are real, including the wage and interest rates. Section 2 develops Aggregate Supply from a matching model of production. The model is referred to as the Kaldor matching model to distinguish it from the original Kaldor model with unequal savings rates. There are three forms of income: labor income from wages (plus transfers from the government), entrepreneurial income, and interest from either ownership of capital needed for production or ownership of national debt. Workers meet entrepreneurs with jobs in a market with frictions, with the number of matches per period determined by a matching function. Individuals who enter the labor market choose between being workers and being entrepreneurs offering jobs to workers. Equilibrium selection of occupation determines an inverse relation between the wage and the interest rate. Output is determined by the level of employment in balanced growth equilibrium times output per match. Section 3 presents the macroeconomic sector, including the government, and determinants of macroeconomic equilibrium. The major theorem is that macroeconomic equilibrium determines the ratio of unemployed to vacancies. Section 4 presents the microeconomic determination of the wage rate for a given interest rate and ratio of unemployed to vacancies. Section 5 derives the balanced growth equilibrium. The major result establishes the effects of the ratio of unemployed to vacancies (determined by macroeconomic equilibrium) on the wage and interest rates. Section 6 extends previous results on efficient levels of unemployment to consider efficient selection of occupations and relations among taxes and unemployment benefits that yield efficient levels of output, entry into the labor market, and selection of occupations. Section 7 presents a positive analysis of the effects on factor prices of government variables, including the ratio of debt to employment, taxes on different types of income, and unemployment benefits. Section 8 presents an alternative analysis of the effects of macroeconomic variables on worker asset values (the present discounted value of being unemployed in the labor market). While some results concerning wage rates are qualified in Section 4, analysis in terms of worker asset values are unambiguous. Extensions to the model are described in Section 9, including a neoclassical production function, a savings rate that depends on the interest rate, and Nash bargaining determination of the wage rate. Section 10 presents conclusions.

\section{Aggregate Supply}

\subsection{Production}

Production at the rate of $p$ per period arises from a fixed proportions production function when a worker is matched with a job offered by an entrepreneur. The job 
requires $k$ units of capital. The capital depreciates at the rate $\delta$ when production is taking place so that the entrepreneur must replace capital at the rate $\delta k$ as production occurs. Matches break up at a rate of $\gamma$ per period, the same for all matches. Matches are formed at a rate determined by a matching function $M(U, V)$, where $U$ is the number of unemployed and $V$ is the number of vacancies in the labor market (see Pissarides, 2000, pp. 6-7, for a discussion of the matching function and Yashiv, 2000, for estimations). The matching function is assumed to have constant returns to scale in $U$ and $V$ and be an increasing, concave function of its arguments. As a result of the assumption of constant returns to scale, the rate of formation of matches per vacancy is $M(U, V) / V=M(U / V, 1)$. Let $\theta=$ $U / V$ and let $m(\theta)=M(\theta, 1)$. Then the rate at which unemployed workers get matches is $M(U, V) / U=m(\theta) / \theta$.

Let $L$ be the total number of individuals in the labor market, either as workers or as entrepreneurs. Let $J$ be the number of jobs and let $E$ be the number of matches between workers and jobs. Assume each entrepreneur can manage $N_{J}$ jobs. With these assumptions,

$$
\begin{aligned}
U & =L-E-J / N_{J} \\
V & =J-E
\end{aligned}
$$

In a balanced growth steady state equilibrium, $L, E, J$ and $\theta$ must satisfy

$$
\begin{aligned}
\frac{d U}{d t} & =-\frac{m(\theta)}{\theta}\left(L-E-J / N_{J}\right)+\gamma E+\rho L-\rho J / N_{J} \\
& =\rho\left(L-E-J / N_{J}\right) \\
\frac{d V}{d t} & =-m(\theta)(J-E)+\gamma E+\rho J=\rho(J-E)
\end{aligned}
$$

The conditions require that unemployment and vacancies grow at the balanced growth rate of $\rho$. In the first line, unemployment declines by the match rate for unemployed workers times the number of unemployed and increases by the rate of match break-ups and balanced growth additions to the labor force seeking employment. This rate of change equals the growth rate times the number of unemployed. In the second line, vacancies decline by the match rate for vacancies times the number of vacancies and increases by the rate of match break-ups and balanced growth increase in jobs. This rate of change equals the growth rate times the number of vacancies. In a balanced growth equilibrium, the unemployment and vacancy rates depend on the rate of growth of the economy, $\rho$, since new workers enter as unemployed and new jobs enter as vacancies. Solving 2.2 for $J$ and $E$ in a balanced growth equilibrium yields:

$$
E=\frac{m(\theta) N_{J} L}{\left(1+\theta N_{J}\right)(\gamma+\rho)+\left(1+N_{J}\right) m(\theta)}
$$




$$
J=\frac{(\gamma+\rho+m(\theta)) N_{J} L}{\left(1+\theta N_{J}\right)(\gamma+\rho)+\left(1+N_{J}\right) m(\theta)}
$$

Although there is no substitution among workers, entrepreneurs and capital in the production function, a given level of employment $E$ can be achieved with different combinations of workers and jobs. This is possible because unemployed workers and vacant jobs are substitutes in the production of matches through the matching function.

\subsection{Workers}

Workers move back and forth between employment and unemployment according to a two-state Markov process with transition rates $m(\theta) / \theta$ and $\gamma$. Let $W_{U}$ and $W_{E}$ be the asset values for an unemployed and an employed worker, respectively. These are the present discounted values of future benefits of working and unemployment. The asset values satisfy

$$
\begin{aligned}
& r W_{U}=\left(1-t_{w}\right) b+(m(\theta) / \theta)\left(W_{V}-W_{U}\right) \\
& r W_{E}=\left(1-t_{w}\right) w+\gamma\left(W_{U}-W_{V}\right)
\end{aligned}
$$

where $r$ is the discount rate, $b$ is the level of unemployment benefits, $t_{w}$ is the tax rate for wages and unemployment benefits, and $w$ is the wage rate. The discount rate is assumed to be the same for all workers and entrepreneurs and equal to the interest rate in the economy. It is possible to solve the system in 2.4 for $W_{U}$ to yield

$$
r W_{U}=\frac{\gamma+r}{\gamma+r+m(\theta) / \theta}\left(1-t_{w}\right) b+\frac{m(\theta) / \theta}{\gamma+r+m(\theta) / \theta}\left(1-t_{w}\right) w
$$

The flow of asset value $r W_{U}$ is therefore a weighted average of the benefits while unemployed and employed, with the weights differing from the unemployment and employment rates because employment is discounted from the future for an unemployed worker (Sattinger, 1985, pp. 11-12).

\subsection{Entrepreneurs and Jobs}

Jobs move between being vacant and being filled according to a two-state Markov process with transition rates $m(\theta)$ and $\gamma$. Let $W_{V}$ and $W_{F}$ be the asset values for a vacant and filled job, respectively. The asset values satisfy

$$
\begin{aligned}
& r W_{V}=-\left(1-t_{p}\right) r k+m(\theta)\left(W_{F}-W_{V}\right) \\
& r W_{F}=\left(1-t_{p}\right)(p-w-\delta k-r k)+\gamma\left(W_{V}-W_{F}\right)
\end{aligned}
$$

where $t_{p}$ is the tax rate on entrepreneurial profits. The entrepreneur pays interest on the capital $k$ when the job is vacant but receives a tax benefit from the loss. 
When filled, a job generates entrepreneurial profits at a rate equal to the rate of production $p$, minus the wage rate $w$, minus depreciation $\delta k$, minus interest payments $r k$. As a minimum requirement for matches to occur, output is assumed to cover depreciation, interest payments, and the minimum wage necessary to exceed unemployment benefits:

$$
p-\delta k-r k-b \geq 0
$$

The system in 2.6 can be solved for the flow of asset value $r W_{V}$ :

$$
r W_{V}=\frac{m(\theta)}{\gamma+r+m(\theta)}\left(1-t_{p}\right)(p-w-\delta k)-\left(1-t_{p}\right) r k
$$

\subsection{Supply of Workers and Entrepreneurs}

Individuals in the labor market are assumed to choose between being workers or entrepreneurs according to which yields the greater asset value, $W_{U}$ or $W_{V} N_{J}$, where $N_{J}$ is the number of jobs an entrepreneur can supervise. The condition for individuals' equilibrium selection between being workers or entrepreneurs is that they should be indifferent between the two activities:

$$
W_{U}=W_{V} N_{J}
$$

This will be referred to as the Equilibrium Selection Condition. This condition can be solved for the wage rate at which it is satisfied:

$$
w=\frac{N_{J} \Phi((p-\delta k-r k) m(\theta)-r k(\gamma+r))-b \theta(\gamma+r)}{m(\theta)\left(N_{J} \Phi+1\right)}
$$

where

$$
\Phi=\frac{1-t_{p}}{1-t_{w}} \frac{(\gamma+r) \theta+m(\theta)}{\gamma+r+m(\theta)}
$$

The number of individuals in the labor market, either as workers or entrepreneurs, is assumed to be an increasing function of the flow of asset value $r W_{U}$. By 2.9, this is the same value whether a person is seeking employment or is an entrepreneur. Suppose the number of individuals in the labor market, $L$, is given by

$$
L=\left(L_{0}\right)^{\rho t}\left(r W_{U}\right)^{\alpha}
$$

where $\rho$ is the rate of growth of the population, $t$ is time, and $\alpha$ is a parameter between zero and one. (The functional form of the labor supply function in 2.12 plays no role in the determination of the equilibrium values of $\theta, w$ and $r$, as will be seen in following sections.) For a constant value of $r W_{U}$, the number of individuals in the labor market will grow at the rate $\rho$ per period. 


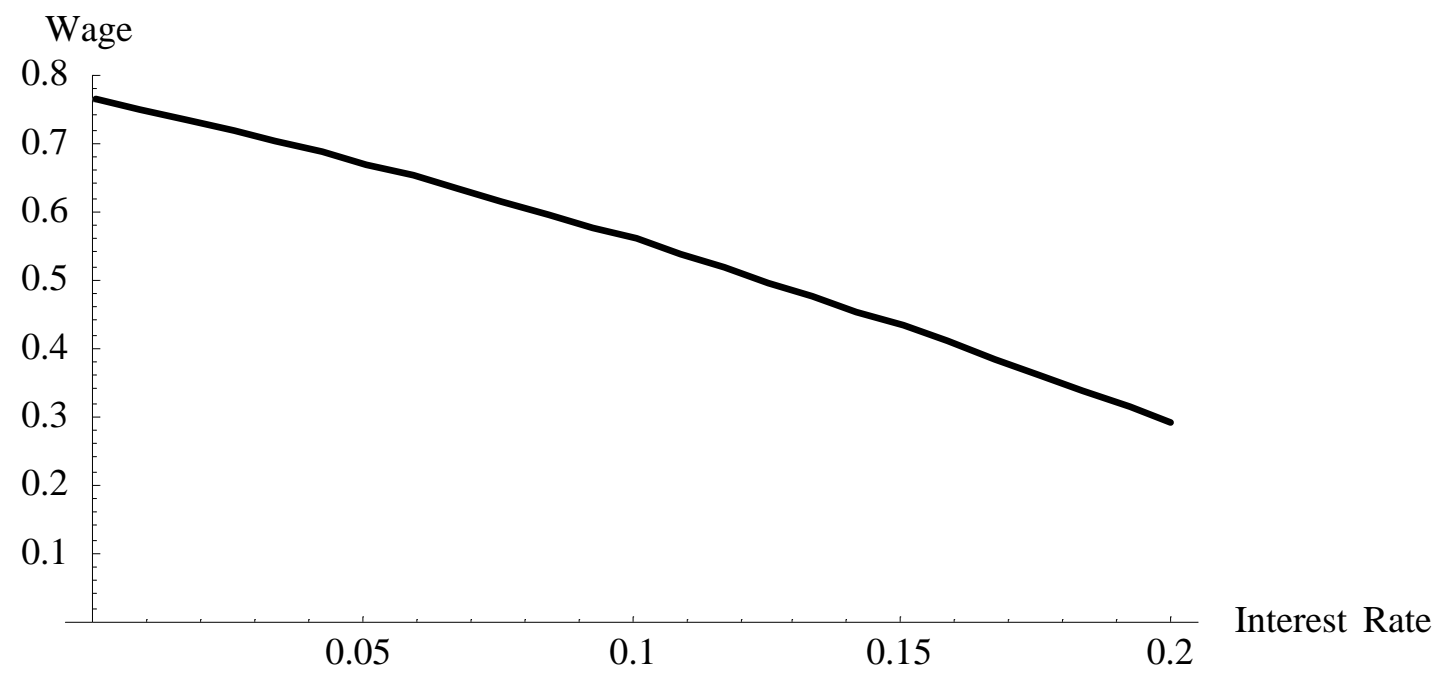

Figure 2.1: Equilibrium Selection Condition

\subsection{Wage and Interest Rates Satisfying the Equilibrium Selection Con- dition}

Aggregate supply, $A S$, is given by production, $E p$. For a given ratio of unemployed to vacancies, $\theta$ (to be determined from macroeconomic equilibrium), different combinations of wage and interest rates will satisfy the equilibrium condition for selection between workers and entrepreneurs in 2.9. The relationship between the wage rate and the interest rate satisfying the Equilibrium Selection Condition in 2.9 for a given value of $\theta$ are shown in Figure 2.1, using a particular matching function and parameter values. ${ }^{2}$ A higher interest rate, which by itself disproportionately lowers $W_{V}$ relative to $W_{U}$, must be accompanied by a lower wage rate so that $W_{U}$ continues to equal $W_{V} N_{J}$. The different combinations of $r$ and $w$ satisfying 2.9 yield different levels of $r W_{U}$.

To this point, assumptions have not been made that completely determine factor payments $w$ and $r$. Those assumptions will be introduced in Section 4 on wage adjustment and will limit the combinations of $w$ and $r$ that will be observed in equilibrium. The next section considers macroeconomic equilibrium and the determination of the ratio of unemployed to vacancies, $\theta$.

\footnotetext{
${ }^{2}$ Figure 2.1 assumes that $p=1, k=2, \delta=.02, \gamma=.03, b=.12, N_{J}=4$, and $t_{w}=t_{p}=.1$. The figure further assumes that the matching function is given by $m(\theta)=\theta /(1+\theta)$ and that macroeconomic equilibrium (to be discussed in the following section) determines $\theta=1$. This matching function is based on $M(U, V)=U V /(U+V)$, which is a Constant Elasticity of Substitution function with elasticity of substitution equal to one-half.
} 


\section{Macroeconomic Equilibrium}

\subsection{Government}

The government taxes labor income, entrepreneurial income and interest income at potentially different tax rates, pays interest at the rate $r$ on the national debt, expands the national debt at the balanced growth rate $\rho$, perhaps runs a deficit or surplus beyond the balanced growth expansion, and distributes the residual in the form of transfers to individuals in the economy. The government's budget constraint can therefore be expressed as

$$
T+\rho D=r D+B+R+b U
$$

where $T$ is the amount of taxes collected, $D$ is the national debt, $B$ is the budget deficit or surplus net of balanced growth changes, $R$ is the level of transfers, and $b U$ is the amount paid out in unemployment benefits. In a balanced growth equilibrium, $B=0$.

Labor income consists of wages, $E w$, plus transfers, $R$, plus unemployment benefits, $b U$, which are taxed at the same rate $t_{w}$. Entrepreneurial income is $E(p-w-\delta k)-J r k$, which is output net of wages and depreciation when a job is filled minus the interest cost of capital incurred whether the job is filled or vacant. Entrepreneurial income is taxed at the rate $t_{p}$. Interest income is given by $J r k+r D$ and is taxed at the rate $t_{r}$. Total taxes in the economy are given by

$$
T=t_{w}(E w+R+b U)+t_{p}(E(p-w-\delta k)-J r k)+t_{r}(J r k+r D)
$$

Rearranging 3.1 assuming $B=0$ yields

$$
R=T+(\rho-r) D-b U
$$

Substituting $T$ from 3.2 and solving for $R$ yields

$$
R=\frac{1}{1-t_{w}}\left(\begin{array}{c}
E\left(w\left(t_{w}-t_{p}\right)+p t_{p}-\delta k\right)-\left(1-t_{w}\right) b U \\
+J r k\left(t_{r}-t_{p}\right)+D\left(\rho-r\left(1-t_{r}\right)\right.
\end{array}\right)
$$

When this expression is used for $R$ in aggregate demand, the government budget constraint is automatically satisfied.

\subsection{Aggregate Demand}

Assume that the savings rate out of after-tax income is a constant $s$, independent of the interest rate $r$. The implications of a savings rate that depends on the interest rate will be discussed later. The savings rate is assumed to be the same 
for all levels of income and all types of income, unlike Kaldor's original model. Income $Y$ is the sum of labor, entrepreneurial and interest income:

$$
Y=E w+b U+R+E(p-w-\delta k)-J r k+J r k+r D
$$

Aggregate Demand, $A D$, is then the proportion of after-tax income that is not saved, $(1-s)(Y-T)$, plus depreciation, $E \delta k$, plus investment needed for balanced growth, $\rho J k$ :

$$
A D=(1-s)(Y-T)+E \delta k+\rho J k
$$

Substituting $R$ from 3.4, $Y$ from 3.5 and $T$ from 3.2 yields:

$$
A D=E((1-s) p+s \delta k)+\rho(J k+(1-s) D)
$$

\subsection{Equilibrium}

Aggregate supply minus aggregate demand can be found by subtracting $A D$ from $E p$ :

$$
\begin{aligned}
A S-A D & =E p-(1-s)(Y-T)-E \delta k-\rho J k \\
& =E s(p-\delta k)-\rho J k-D(1-s)
\end{aligned}
$$

The notable feature of this expression for $A S-A D$ is that $r, b, t_{w}, t_{p}$ and $t_{r}$ do not directly appear. This occurs because transfers $R$ are the residual of government revenues net of unemployment benefits and the savings rate $s$ is the same for all income types. The variables then redistribute production among income types, all of which have the same savings rate, without affecting the difference between aggregate supply and aggregate demand. The variables may affect $W_{U}$ and $L$, but $E, J$ and $D$ will all be proportional to $L$ in balanced growth, so that $E, J$ and $D$ are sufficient to determine $A S-A D$.

In macroeconomic equilibrium, Aggregate Supply equals Aggregate Demand, so $A S-A D=0$. This condition can also be viewed as stating that in balanced growth macroeconomic equilibrium, national savings, $E s(p-\delta k)-D(1-s)$, equals investment, $\rho J k$. Setting $A S-A D$ equal to zero and dividing by $E$ yields a condition on the ratio of jobs to employment:

$$
\frac{J}{E}=\frac{s(p-\delta k)}{\rho k}-\frac{1-s}{\rho k} \frac{D}{E}
$$

Equality between $A S$ and $A D$ determines $J / E$ because national savings (for a given ratio of national debt to employment) depends on $E$ while investment in balanced growth depends on $J$. The ratio $J / E$ must exceed one for vacancies to 
be positive. For this to occur in a balanced growth equilibrium, the following government debt constraint must hold:

$$
\frac{D}{E}<\frac{s(p-\delta k)}{1-s}-\frac{\rho k}{1-s}
$$

The following lemma is a direct result of 3.9:

Lemma 3.1. Comparing alternative balanced growth equilibria in the Kaldor matching model, and assuming the government debt constraint holds, the ratio of jobs to employment will be greater for greater values of $s$ and $p$, and will be smaller for greater values of $\rho, \delta, k$, and $D / E$.

Now consider the relation between the ratio of jobs to employment, $J / E$, and $\theta$, the ratio of unemployed to vacancies. Divide the second equality of 2.2 by $E$ and rearrange to get

$$
\frac{J}{E}=\frac{\gamma+\rho}{m(\theta)}+1
$$

Since $m(\theta)$ is an increasing function of $\theta$, the following lemma holds:

Lemma 3.2. The ratio of jobs to employment, $J / E$, is a decreasing function of the ratio of unemployed to vacancies, $\theta$.

Combining Lemmas 3.1 and 3.2 yields the following theorem.

Theorem 3.3. In the Kaldor matching model, the ratio of unemployment to vacancies, $\theta$, is determined in a balanced growth equilibrium by the condition that Aggregate Demand equal Aggregate Supply. With the government debt constraint holding, the ratio $\theta$ is greater for greater values of $\rho, \delta, k$, and $D / E$ and smaller for greater values of $s$ and $p$.

In the original Kaldor model, parameters that raise investment increase the proportion of income going to profits, out of which the savings rate is greater. Also in that model, parameters that raise savings reduce the proportion of income going to profits. By comparison, in this model, the parameters $\rho, \delta$, and $k$ raise investment and therefore require a lower value of $J / E$ and a higher ratio $\theta$. Higher values of $s$ and $p$ raise savings and have opposite effects on $J / E$ and $\theta$.

Although dynamics will be deferred to a later paper, an important question concerns whether there is a mechanism that brings about macroeconomic equilibrium. Specifically, what causes the ratios $J / E$ and $\theta$ to change so that 3.9 is satisfied? For a given value of $D / E$, increases or decreases in $L$ will not bring about macroeconomic equilibrium. A change in $L$ would alter $J$ and $E$ in the 
same proportion, leaving $\theta$ and $A S-A D$ unaffected. However, if $A S>A D$, the number of jobs could increase relative to the level of employment in response to a fall in the interest rate that raised $W_{V}$ relative to $W_{U}$. Since $A S-A D$ is essentially national savings minus investment, the fall in the interest rate is a response consistent with the market for loanable funds. Even though the adjustment mechanism relies on changes in the interest rate, the condition $A S=A D$ in 3.9 is consistent with different values of $r$ but only single values of $J / E$ and $\theta$. Interest rate changes therefore provide a mechanism that ensures satisfaction of macroeconomic equilibrium without restricting the interest rate that occurs in equilibrium. Determination of the combination of wage and interest rate that will arise in equilibrium will be considered in the following section.

\section{Wage Adjustment}

A standard assumption in the literature regarding factor price determination in matching and search models is Nash Bargaining (Pissarides, 2000, pp. 15-18). Based on market outcomes, workers and entrepreneurs optimally choose reservation wages and profits. The surplus from a match, given by the difference between production and the sum of the reservation wage of the worker and the reservation profit of the entrepreneur, is then divided between the worker and the entrepreneur, with a proportion $\beta$ going to the worker. In the Markov processes arising in the Kaldor matching model, the reservation values for the worker and entrepreneur are given by $r W_{U}$ and $r W_{V}$, respectively. Although the Nash Bargaining assumption could be applied here, it does not necessarily result in efficient trade-offs between workers and entrepreneurs.

Instead of bargaining between workers and entrepreneurs, the wage mechanism developed in Sattinger (1990) will be assumed. Entrepreneurs announce their wages prior to a match so that no bargaining occurs (this is sometimes described as wage posting). By offering a higher wage, entrepreneurs can attract a higher number of applicants per period, thereby lowering the time it takes to fill a vacancy. In response to a higher wage with an entrepreneur, the number of applicants per period rises until the value of seeking employment with the entrepreneur equals the value of seeking employment elsewhere in the labor market. With this adjustment in the number of applicants as a constraint on the choice of wage, the entrepreneur maximizes its asset value $W_{V}$ with respect to the wage. In equilibrium, the optimal wage for an entrepreneur equals the wage prevailing in the market, and the number of applicants per period for a vacancy equals the ratio of unemployed to vacancies in the labor market, $\theta$. The maximization problem of the entrepreneur ensures that the entrepreneur and worker have the same tradeoffs between the wage, $w$, and the ratio of unemployed to vacancies, $\theta$. This is a 
necessary condition for efficiency and eliminates search congestion in the model developed by Sattinger (1990).

Applying this approach in the Kaldor matching model, the worker asset value $W_{U}$ offered by a particular entrepreneur can be found from 2.5 as a function of the entrepreneur's wage and the number of applicants per period (which is the entrepreneur's value of $\theta$ ). Setting the entrepreneur's value of $W_{U}$ equal to the value in the rest of the labor market, the entrepreneur's value of $\theta$ can be expressed as a function of the entrepreneur's wage, the market wage, and the market value of $\theta$. This function for the entrepreneur's value of $\theta$ is then substituted into the expression for the entrepreneur's asset value $W_{V}$ in 2.8. The optimal entrepreneur wage, as a function of the market wage and the market value of $\theta$, is obtained by differentiating this expression for $W_{V}$ (incorporating the response of the entrepreneur's value of $\theta$ ) with respect to the entrepreneur's wage. Equilibrium occurs when this derivative equals zero with the entrepreneur wage equal to the market wage. This condition can then be solved for the wage as a function of the market value of $\theta$, the interest rate, and parameters of the model. This yields a solution where the entrepreneur's asset value $W_{V}$ is tangent to the worker's asset value $W_{U}$ in a graph of wage versus $\theta$. An alternative derivation exploits this feature of the solution by deriving the worker's and entrepreneur's marginal rates of substitution between the wage and $\theta$, setting them equal, and solving for the wage. Applying this procedure in the Kaldor matching model yields

$$
w=\frac{\left((p-\delta k) m^{\prime}(\theta)+b\left(m(\theta)-\theta m^{\prime}(\theta)\right)\right)(\gamma+r+m(\theta))}{m(\theta)\left(\gamma+r+m(\theta)+(1-\theta) m^{\prime}(\theta)\right)}
$$

This will be referred to as the Entrepreneur Optimization Condition.

\section{Balanced Growth Equilibrium}

With wage adjustment determined by 4.1 , the balanced growth equilibrium can be found. The solution takes the following steps.

- Macroeconomic equilibrium determines $J / E$ in 3.9 .

- Balanced growth flows between unemployed and employed for workers and between filled and vacant for jobs in 2.2 determine $\theta$.

- The Equilibrium Selection Condition in 2.9 determines the wage rate as a function of $r$ and $\theta$ such that individuals are indifferent between being workers and being entrepreneurs. 


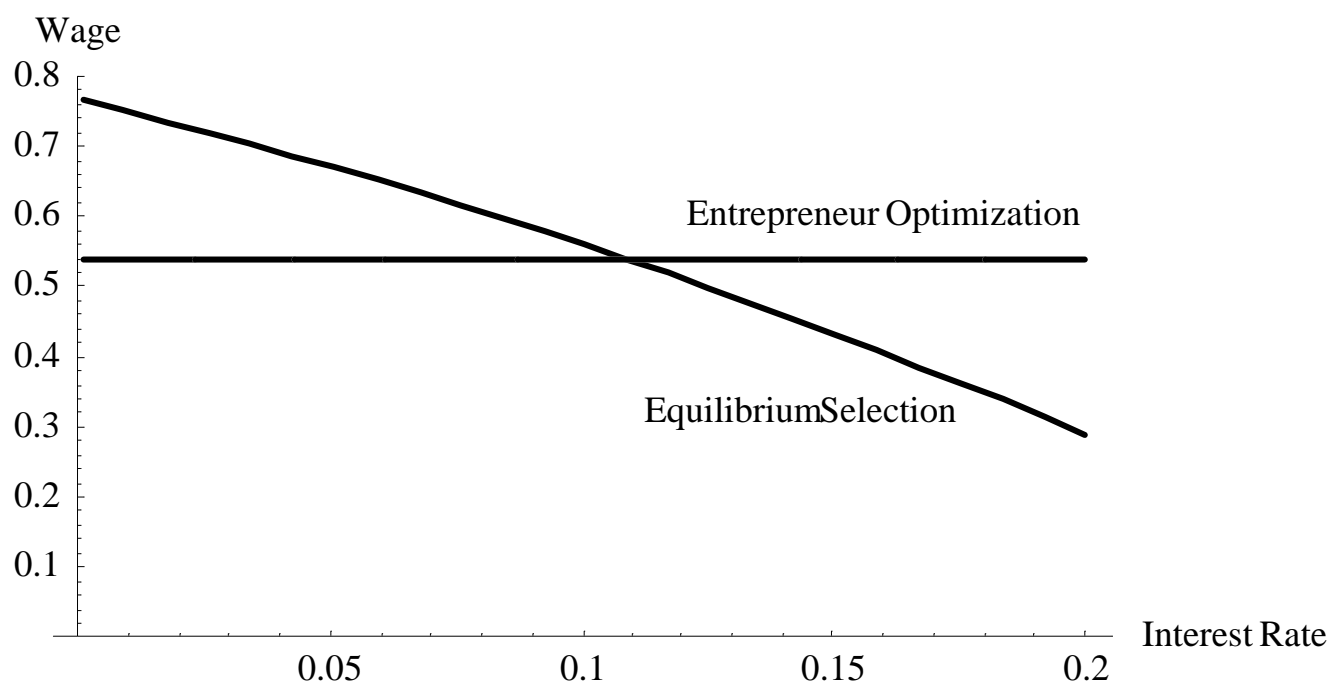

Figure 5.1: Determination of Wage and Interest Rate

- Setting the function for the wage rate in the previous step equal to the wage rate in 4.1 from the Entrepreneur Optimization Condition determines the interest rate, given $\theta$ as determined from macroeconomic equilibrium.

- With the interest rate and $\theta$ determined, the wage can be found from 4.1.

- With $r, w$ and $\theta$ determined, the asset values can be calculated and labor supply $L$ can be found from 2.12 .

- The levels of $J$ and $E$ can be found from 2.2 along with the unemployment and vacancy rates.

The relation between parameters of the model in Theorem 3.3 and the wage and interest rate can be found by considering the determination of $w$ and $r$ given the value of $\theta$ from macroeconomic equilibrium. Figure 5.1 shows the two relations between the wage and the interest rate determined by the Equilibrium Selection Condition in 2.9 and by the Entrepreneur Optimization Condition in 4.1 for a given value of $\theta$, using the same assumptions as for Figure 2.1. While the interest rate will be shown in this section to be unambiguously greater for higher values of $\theta$, the effects of $\theta$ on $w$ require qualification.

The effects of $\theta$ on the interest rate can be found by incorporating the Entrepreneur Optimization Condition into the Equilibrium Selection Condition. Consider the ratio of asset values, $W_{U} / W_{V}$. With the wage determined by the Entrepreneur 
Optimization Condition in 4.1,

$$
\frac{W_{U}}{W_{V}}=\frac{\left(1-t_{w}\right)\left((p-\delta k) m^{\prime}(\theta)+b\left(\gamma+r+m(\theta)-\theta m^{\prime}(\theta)\right)\right)}{\left(1-t_{p}\right)\left((p-\delta k-b-r k)\left(m(\theta)-\theta m^{\prime}(\theta)\right)-r k\left(\gamma+r+m^{\prime}(\theta)\right)\right)}
$$

where $m^{\prime}(\theta)=d m(\theta) / d \theta$. In this expression, $p-\delta k-b-r k$ must be positive from 2.7. Also, the amounts $m^{\prime}(\theta)$ and $m(\theta)-\theta m^{\prime}(\theta)$ are the marginal contributions to the number of matches of an unemployed worker and a vacant job, respectively, and are both positive. ${ }^{3}$ Then an increase in the interest rate raises the numerator and reduces the denominator, so that the ratio is an increasing function of the interest rate. Equilibrium occurs when the ratio $W_{U} / W_{V}$ equals $N_{J}$, the ratio consistent with the Equilibrium Selection Condition.

Existence of equilibrium can be established as follows. At some positive interest rate, the denominator is zero. For interest rates between zero and this interest rate, the ratio $W_{U} / W_{V}$ is an increasing function of the interest rate. Also, the ratio $W_{U} / W_{V}$ increases indefinitely as the interest rate approaches (from below) the interest rate at which the denominator is zero. A solution exists if, at $r=0$, the ratio $W_{U} / W_{V}$ is less than $N_{J}$. Figure 5.2 shows the determination of the interest rate using the same assumptions as for Figure 2.1. Equilibrium occurs where the ratio $W_{U} / W_{V}$ crosses the horizontal line at $N_{J}$.

Now consider how the curve shifts when $\theta$ increases. From assumptions about the matching function, $m^{\prime}(\theta)$ is a decreasing function of $\theta$ and $m(\theta)-\theta m^{\prime}(\theta)$ is an increasing function of $\theta$. The denominator is an increasing function of $\theta$. For sufficiently small $b$, the numerator will also be a decreasing function of $\theta$. (The possibility that the numerator is an increasing function of $\theta$ arises because a higher ratio of unemployed to vacancies raises the proportion of time a worker spends collecting unemployment benefits.) In general, however, a higher ratio of unemployed workers to vacancies makes workers worse off and entrepreneurs better off, shifting the $W_{U} / W_{V}$ curve downward, so that the equilibrium interest rate increases. This increase in the interest rate from a higher value of $\theta$ is illustrated in Figure 5.2. Combining these results with Theorem 3.3 yields the following.

Theorem 5.1. In the Kaldor matching model with the government debt constraint holding and for sufficiently small $b$, a higher value of $\theta$ (from greater values of $\rho, \delta, k$ or lower values of $s$ and $p$ ) yields a higher interest rate.

Next, consider the effects of $\theta$ on the wage rate. When $\theta$ increases, the curve relating the wage and interest rate from the Entrepreneur Optimization Condition shifts down while the curve from the Equilibrium Selection Condition shifts

\footnotetext{
${ }^{3}$ Since $M(U, V)$ has constant returns to scale, $M(U, V)$ equals $U \partial M / \partial U+V \partial M / \partial V$. By assumption, $\partial M / \partial U$ and $\partial M / \partial V$ are positive and homogeneous of degree zero. Then $\partial M / \partial U=$ $\partial M(\theta, 1) / \partial \theta=m^{\prime}(\theta)>0$ and $\partial M / \partial V=M(U, V) / V-(U / V) \partial M / \partial U=m(\theta)-\theta m^{\prime}(\theta)$.
} 


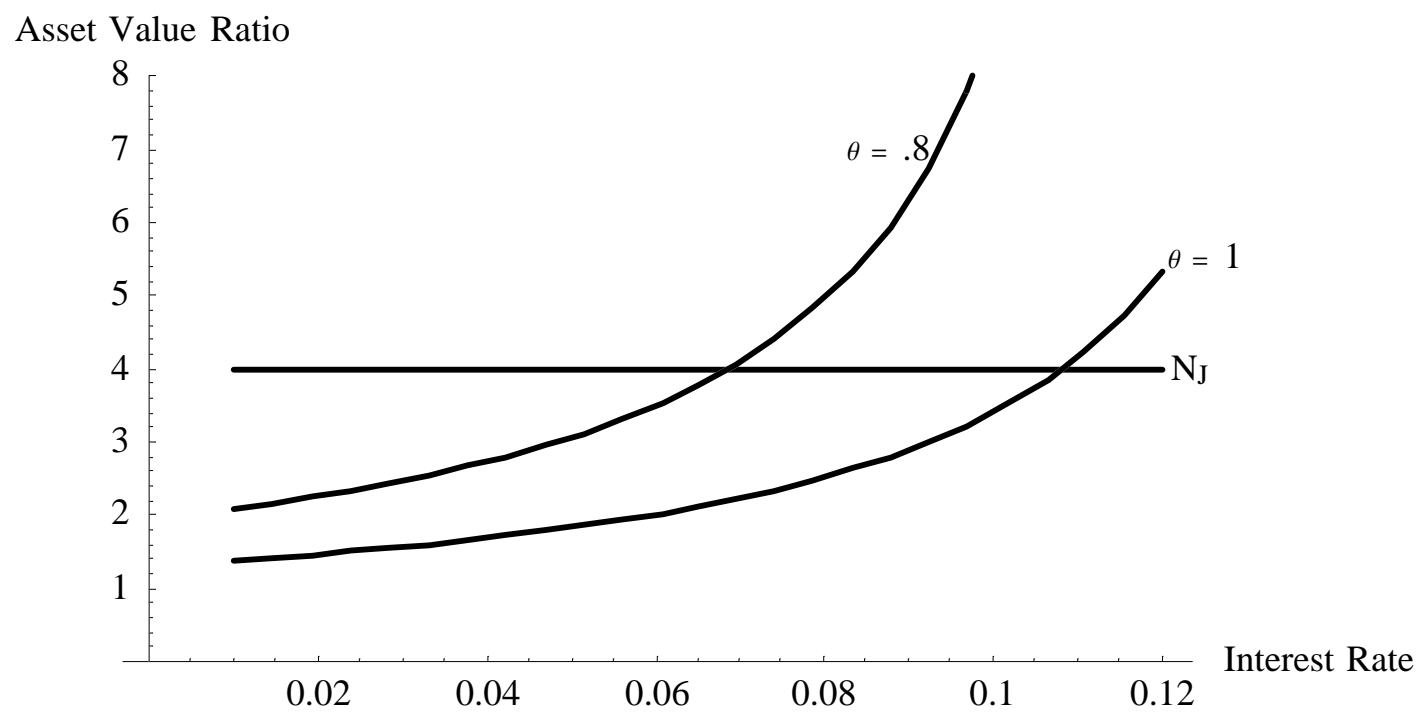

Figure 5.2: Effect of $\theta$ on Interest Rate

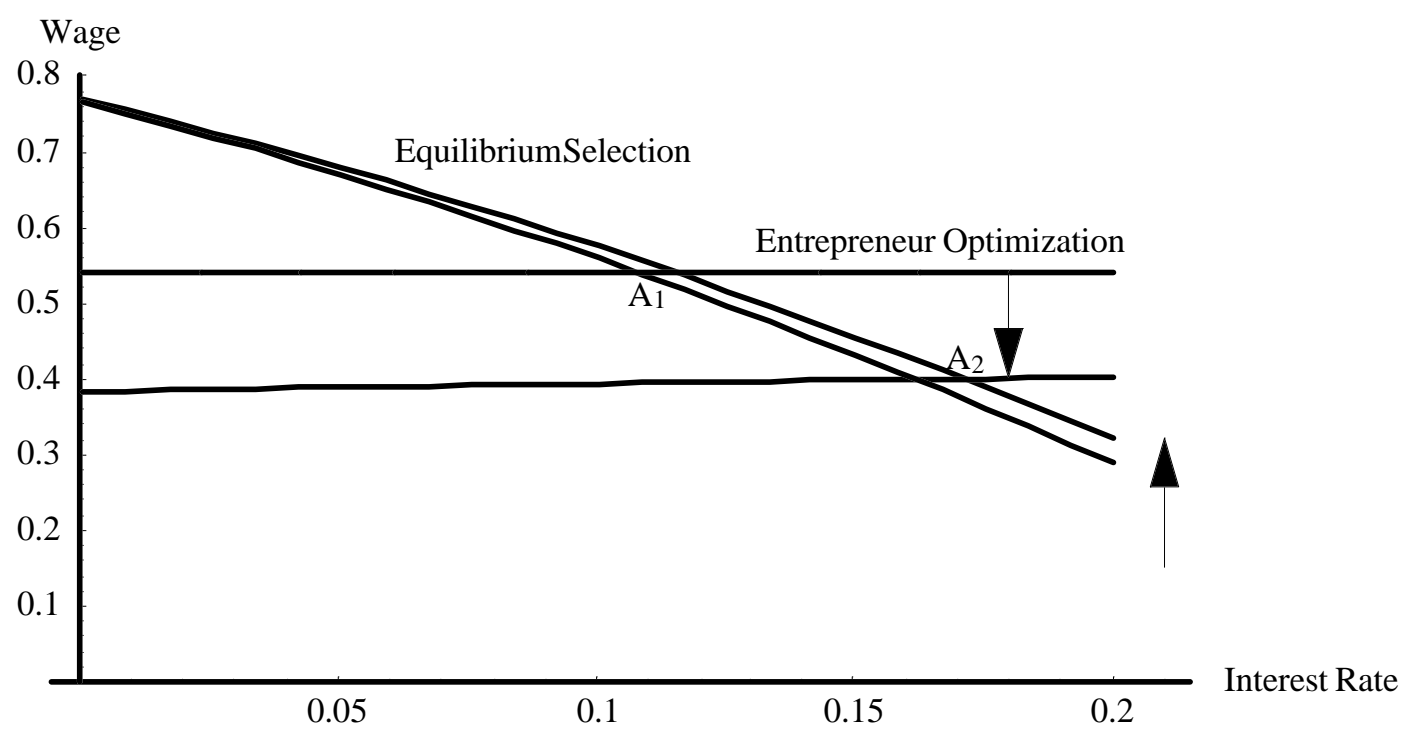

Figure 5.3: Effect of $\theta$ on Wage Rate 
up, as illustrated in Figure 5.3. The slope of the curve from the Entrepreneur Optimization Condition depends on $\theta$. From 4.1, when $\theta<1,(1-\theta) m^{\prime}(\theta)$ is positive so that an increase in $r$ reduces $w$. Then the curve from the Entrepreneur Optimization Condition is downward sloping. When $\theta>1,(1-\theta) m^{\prime}(\theta)$ is negative and the curve from the Entrepreneur Optimization Condition is upward sloping, and when $\theta=1$, the curve is horizontal. This result is summarized in the following lemma for future reference.

Lemma 5.2. In the Kaldor matching model, the curve relating the wage to the interest rate (for a given ratio of unemployed to vacancies, $\theta$ ) and satisfying the Entrepreneur Optimization Condition is upward sloping if $\theta>1$, downward sloping if $\theta<1$, and horizontal if $\theta=1$.

If $\theta$ starts at 1 and increases, the new curve from the Entrepreneur Optimization Condition will lie entirely below the old one. The new equilibrium wage must lie on the new curve, so that the wage will decline as a result of the increase in $\theta$. By continuity, the wage will be a decreasing function of $\theta$ when $\theta$ is sufficiently close to one. When $\theta$ is less than one, the curve from the Entrepreneur Optimization Condition is downward sloping. Then the wage will be a declining function of $\theta$ for all $\theta$ less than one, since the wage will first decline from the downward shift in the curve for the Entrepreneur Optimization Condition (holding the interest rate fixed) and then will decline further from the increase in the interest rate (moving along the curve for the Entrepreneur Optimization Condition to the new equilibrium). These results are summarized as follows.

Theorem 5.3. In the Kaldor matching model with the government debt constraint holding, a higher value of $\theta$ (from greater values of $\rho, \delta, k$ or lower values of $s$ and $p$ ) yields a lower wage rate if $\theta$ is sufficiently near one or if $\theta$ is less than one.

In Figure 5.3, illustrating the effects of an increase in $\theta$, the wage change needed to satisfy the Entrepreneur Optimization Condition (at the former interest rate) is much greater than the change needed to satisfy the Equilibrium Selection Condition (at the former interest rate). The downward shift in the curve for the Entrepreneur Optimization Condition therefore dominates, resulting in a lower wage rate. Although a positive relation between $\theta$ and $w$ is not ruled out by Theorem 5.3, analysis of flows of worker asset values in Section 8 does not require qualifications. 


\section{Efficiency}

The question of efficient levels of unemployment has been posed in the context of search congestion (Phelps, 1972; Tobin, 1972; Diamond, 1982; Mortensen, 1982; Pissarides, 1984). Hosios (1990) established conditions on the share of surplus going to workers in Nash Bargaining that yield efficiency and Sattinger (1990) described a market mechanism that eliminates search congestion and yields the Hosios conditions. Efficient taxation has an extensive literature (see Erosa and Gervais (2000) for a life-cycle approach).

Several approaches to conditions for efficiency are possible. In a straightforward approach, social welfare may be taken to equal the flow of output (net of depreciation), minus the opportunity costs of participation in the labor market and minus the opportunity cost of the capital used in the output. The flow of output net of depreciation in the Kaldor matching model is given by $E(p-\delta k)$, the level of participation in the labor market is $L$, and the capital used is $J k$. One could then compare contributions to the flow of output to opportunity costs of participation and capital. Alternatively, one could construct a social welfare function from the asset values of workers and entrepreneurs, and include trans-

fers, taxes and interest on capital and on the debt. One may expect the sum to equal the flow of output $E(p-\delta k)$ since the government and employment only redistribute the production, and the construction of the asset value equations redistribute the value of production between employment and unemployment, or between filled and vacant. However, this is not the case with positive balanced growth. Summing asset values with balanced growth includes entering workers and entrepreneurs who experience asset values without currently producing anything. It is therefore necessary to work with the flow of output, $E(p-\delta k)$.

In Diamond's approach, conditions for efficient levels of unemployment arise by comparing the marginal product of an entering worker with the private return (and foregone opportunity) of an entering worker. This approach will be followed here. In the context of the Kaldor matching model, an individual entering the labor market could become either a worker or an entrepreneur. An increase in $L$ results in the long run in proportional increases in $E$ and $J$, leaving $\theta, w$ and $r$ unaffected. While the long run consequences of an additional person in the labor market can be easily calculated, it is necessary to consider the transition over time to the new balanced growth equilibrium in calculating the marginal product of an additional person in the labor market. This can be done using a result developed by Diamond (1980). However, Diamond's method is based on movement between steady state equilibria with a differential equation for the economic variable that is independent of time. This is not the case with balanced growth but a change of variables can be used to eliminate the time variable in the differential equation, 
thereby adapting Diamond's method to a balanced growth context.

Let $h\left(t, E, L_{0}, J_{0}\right)$ be the rate of change of $E$ as a function of $t, E, L_{0}$ and $J_{0}$ :

$$
\begin{aligned}
h\left(t, E, L_{0}, J_{0}\right) & =\frac{d E}{d t}=m(\theta) V-\gamma E \\
& =m\left(\frac{L_{0} e^{\rho t}-\left(J_{0} e^{\rho t} / N k\right)-E}{J_{0} e^{\rho t}-E}\right)\left(J_{0} e^{\rho t}-E\right)-\gamma E
\end{aligned}
$$

where $L_{0}$ and $J_{0}$ are treated as parameters and $L$ and $J$ grow at the balanced growth rate $\rho$. In a balanced growth equilibrium, $E$ will also grow at rate $\rho$ and $d E / d t$ will equal $\rho E$. Let $\widehat{E}=E / e^{\rho t}$. Then $d E / d t=\rho \widehat{E} e^{\rho t}+e^{\rho t} d \widehat{E} / d t$. Substituting into 6.1 , dividing by $e^{\rho t}$ and rearranging yields

$$
f\left(\widehat{E}, L_{0}, J_{0}\right)=\frac{d \widehat{E}}{d t}=m\left(\frac{L_{0}-\left(J_{0} / N k\right)-\widehat{E}}{J_{0}-\widehat{E}}\right)\left(J_{0}-\widehat{E}\right)-\gamma \widehat{E}-\rho \widehat{E}
$$

In a balanced growth equilibrium $f\left(\widehat{E}, L_{0}, J_{0}\right)$ will equal zero. The long run change in $\widehat{E}$ from a change in $L_{0}$ is $\left(-\partial f / \partial L_{0}\right) /(\partial f / \partial \widehat{E})$, holding $J_{0}$ constant. In discounting a future value of $E$ in terms of $\widehat{E}$, the value is reduced by the discount rate $r$ but increased by the growth rate in $E$ relative to $\widehat{E}$ of $\rho$. This is accomplished by using a discount rate of $r-\rho$ applied to $\widehat{E}$. In Diamond's method, the present discounted value of the movement from the original balanced growth equilibrium to the new balanced growth equilibrium as a result of an increase in $L_{0}$ is given by:

$$
\frac{\partial f / \partial L_{0}}{(r-\rho)(r-\rho-\partial f / \partial \widehat{E})}
$$

In the of absence growth (that is, when $\rho=0$ ), an increase in $L_{0}$ yields an increase in the labor force of one individual per period indefinitely into the future, for a present value of $1 / r$. Since $L$ increases by the growth rate $\rho$, the present value of the increase in the labor force is $1 /(r-\rho)$. To obtain the marginal product of an additional person in the labor force, it is therefore necessary to multiply 6.3 by $(r-\rho) / r$ to correct for the differing amount of labor in balanced growth. Applying this correction and multiplying by the production net of depreciation of an additional employed person yields:

$$
M P_{L}=\frac{\left(\partial f / \partial L_{0}\right)(p-\delta k)}{r(r-\rho-\partial f / \partial \widehat{E})}
$$

By inspection of 6.2 , the terms in the growth rate $\rho$ will cancel out, so that the marginal product of labor does not depend on the growth rate. 
Applying Diamond's procedure yields:

$$
M P_{L}=\frac{(p-\delta k) m^{\prime}(\theta)}{r\left(\gamma+r+m(\theta)+(1-\theta) m^{\prime}(\theta)\right)}
$$

A necessary condition for efficiency is that this marginal product equal the private return to an individual considering entry as an unemployed worker, given by the asset value $W_{U}$ in 2.5. With the wage determined by firm optimization in 4.1, substitution yields:

$$
W_{U}=\frac{\left(1-t_{w}\right)\left((p-\delta k) m^{\prime}(\theta)+b\left(\gamma+r+m(\theta)-\theta m^{\prime}(\theta)\right)\right)}{r\left(\gamma+r+m(\theta)+(1-\theta) m^{\prime}(\theta)\right)}
$$

Setting $M P_{L}$ from 6.5 equal to $W_{U}$ from 6.6 and solving yields a relation between unemployment benefits $b$ and the tax rate on labor income, $t_{w}$, such that entry is efficient:

$$
b=\frac{t_{w}}{1-t_{w}} \frac{p-\delta k}{\gamma+r+m(\theta)-\theta m^{\prime}(\theta)}
$$

If this condition does not hold, a Pareto improvement is possible since current labor force participants could compensate a marginal entrant to enter (if $M P_{L}>$ $W_{U}$ ) or stay out (if $M P_{L}<W_{U}$ ). If unemployment benefit $b$ is zero, then $t_{w}$ must be zero for efficient entry. However, if $t_{w}$ is positive, there exists a positive level of unemployment benefit such that entry is efficient. ${ }^{4}$ The positive unemployment benefit compensates for the distorting effects of $t_{w}$ on decisions to enter the labor force.

A second condition for efficiency arises from considering changes in the number of jobs, $J$. If the number of jobs increases, holding total labor force participation $L$ fixed, individuals are shifted from seeking jobs to being entrepreneurs. An efficient selection of individuals to be entrepreneurs requires that this net product (equal to the present value of the marginal product of entrepreneurs minus the marginal product of the foregone labor and the opportunity cost of capital) equal zero. Using Diamond's method, the net product is given by:

$$
\begin{aligned}
N P_{J} & =\frac{\left(\partial f / \partial J_{0}\right)(p-\delta k)}{r(r-\rho-\partial f / \partial \widehat{E})}-k \\
& =\frac{(p-\delta k)\left(N_{J} m(\theta)+\left(1+N_{J} \theta\right) m^{\prime}(\theta)\right)}{r N_{J}\left(\gamma+r+m(\theta)+(1-\theta) m^{\prime}(\theta)\right)}-k
\end{aligned}
$$

The conditions for efficiency carry strong implications for the determination of economic and policy variables. Setting $N P_{J}$ equal to zero determines the interest

\footnotetext{
${ }^{4}$ The condition can also be interpreted as determining the ratio $\theta$ that must hold when $t_{w}$ and $b$ are positive.
} 
rate that must hold for efficient selection at a particular value of $\theta$. This interest rate does not depend on the tax rates or unemployment benefits. Substituting the interest rate needed for efficiency into 6.5 determines a value for the marginal product of labor. The worker asset value $W_{U}$ must equal this value for efficient entry. If there is a positive tax on labor, $t_{w}$, the unemployment benefit $b$ must be positive from 6.7 so that $W_{U}$ stays equal to $M P_{L}$ and efficient entry occurs. (That is, the combinations of $b$ and $t_{w}$ from 6.7 yield a constant value of $W_{U}$.) If $t_{w}=0$, then $b=0 .{ }^{5}$ Positive values of $b$ and $t_{w}$ may leave $W_{U}$ unaffected, but a positive value of $b$ raises the wage from the Entrepreneur Optimization Condition in 4.1 and thereby reduces $W_{V}$. To keep the ratio $W_{U} / W_{V}$ equal to $N_{J}$, the tax on profits must be negative, i.e., entrepreneurial activity must be subsidized.

The determination of the interest rate from $N P_{J}=0$ can be understood in terms of the increased output generated by more capital. The addition of $k$ units of capital allows $1 / N_{J}$ units of labor to be shifted from working to being an entrepreneur for a job. With the added output generated by the entrepreneur exceeding the foregone output generated by the $1 / N_{J}$ units of labor, production increases. The efficiency condition $N P_{J}=0$ requires that $k$ units of capital equal the present value of this production increase.

The conclusions concerning the efficiency of the Kaldor matching model are summarized in the following theorem.

Theorem 6.1. Suppose that a balanced growth equilibrium holds in the Kaldor matching model, with the government debt constraint holding. Efficient selection determines the interest rate from 6.8 and efficient selection and entry together determine the worker asset value when unemployed, $W_{U}$. For a given tax rate on labor income $t_{w}$, the level of unemployment benefit that yields efficient entry is given by 6.7. A positive tax rate on labor income, $t_{w}$, requires a positive unemployment benefit $b$ and a subsidy of entrepreneurial profits.

Figure 6.1 shows the unemployment benefit $b$ as a function of the labor tax, $t_{w}$, from 6.7 using the other assumptions from Figure 2.1. Figure 6.2 shows the efficient tax on profits as a function of the labor tax, assuming the unemployment benefit $b$ is also efficient. As shown, the tax on profits is negative when $t_{w}>0$, so that entrepreneurial activity should be subsidized for efficiency when the tax on labor income is positive.

Although entrepreneurial profits must be subsidized for efficiency when the tax on labor income is positive, the net tax collections can still be positive, as shown in Figure 6.3.

\footnotetext{
${ }^{5}$ Efficient entry occurs when $t_{w}=b=0$ because of the efficiency properties of the Entrepreneur Optimization Condition.
} 


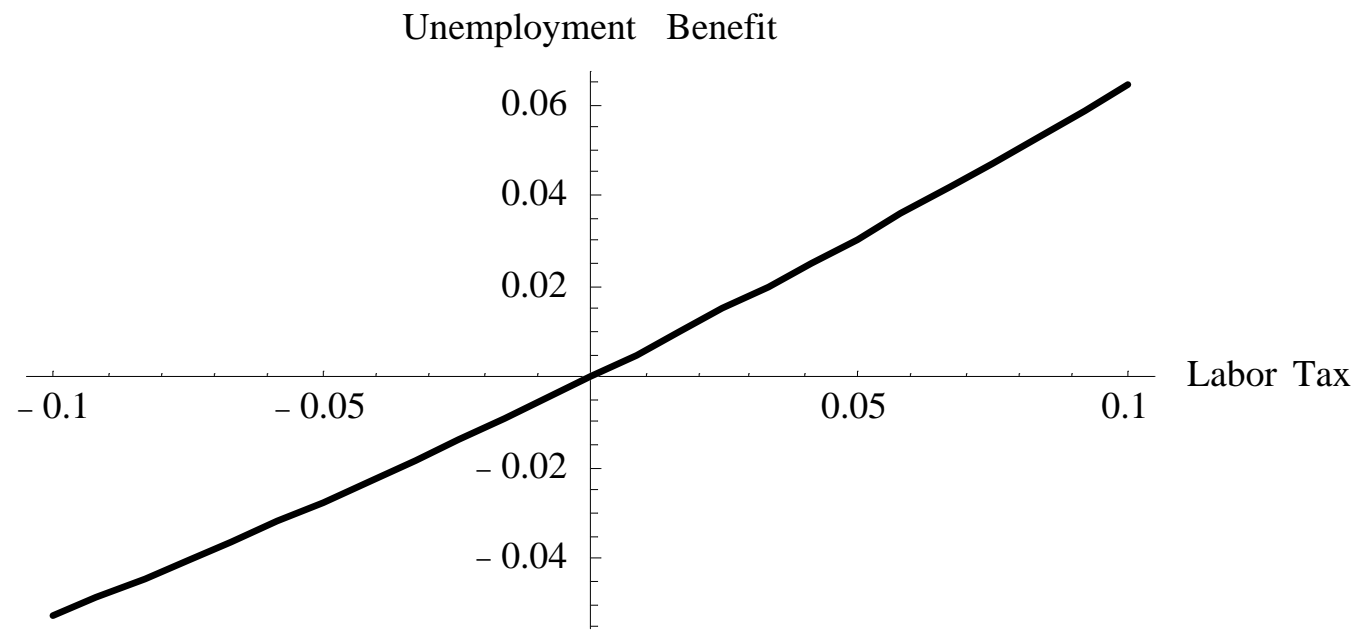

Figure 6.1: Efficient Unemployment Benefit

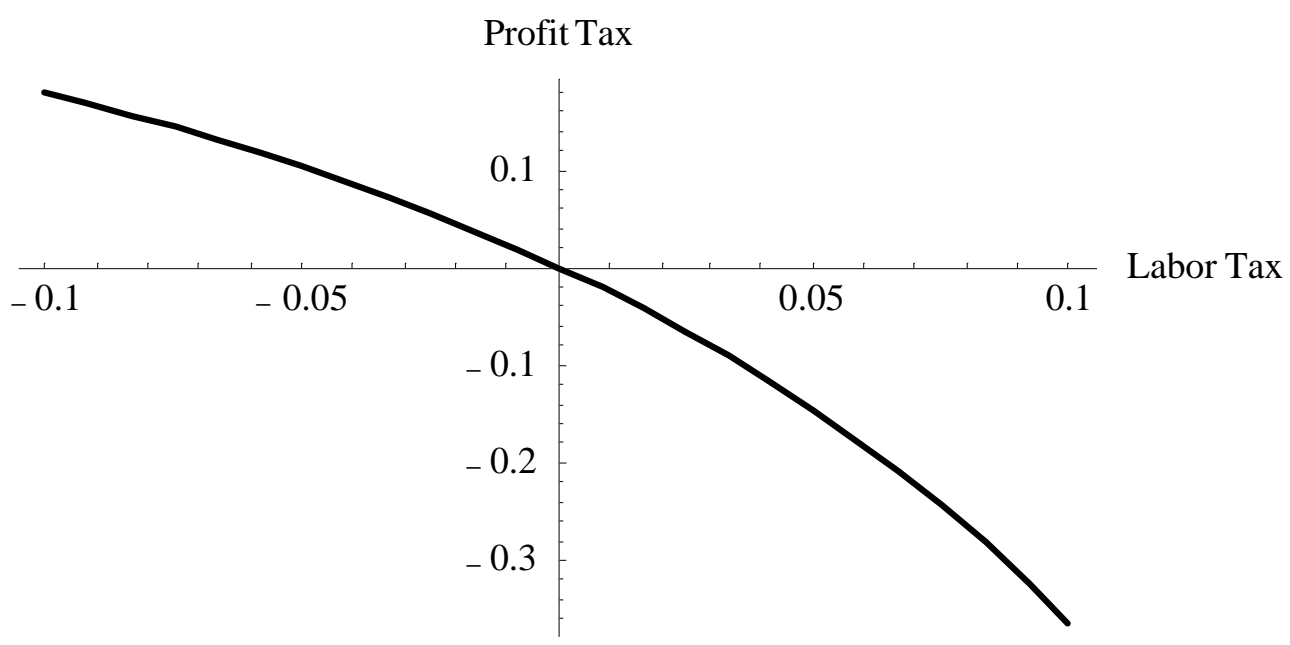

Figure 6.2: Efficient Tax on Profits 


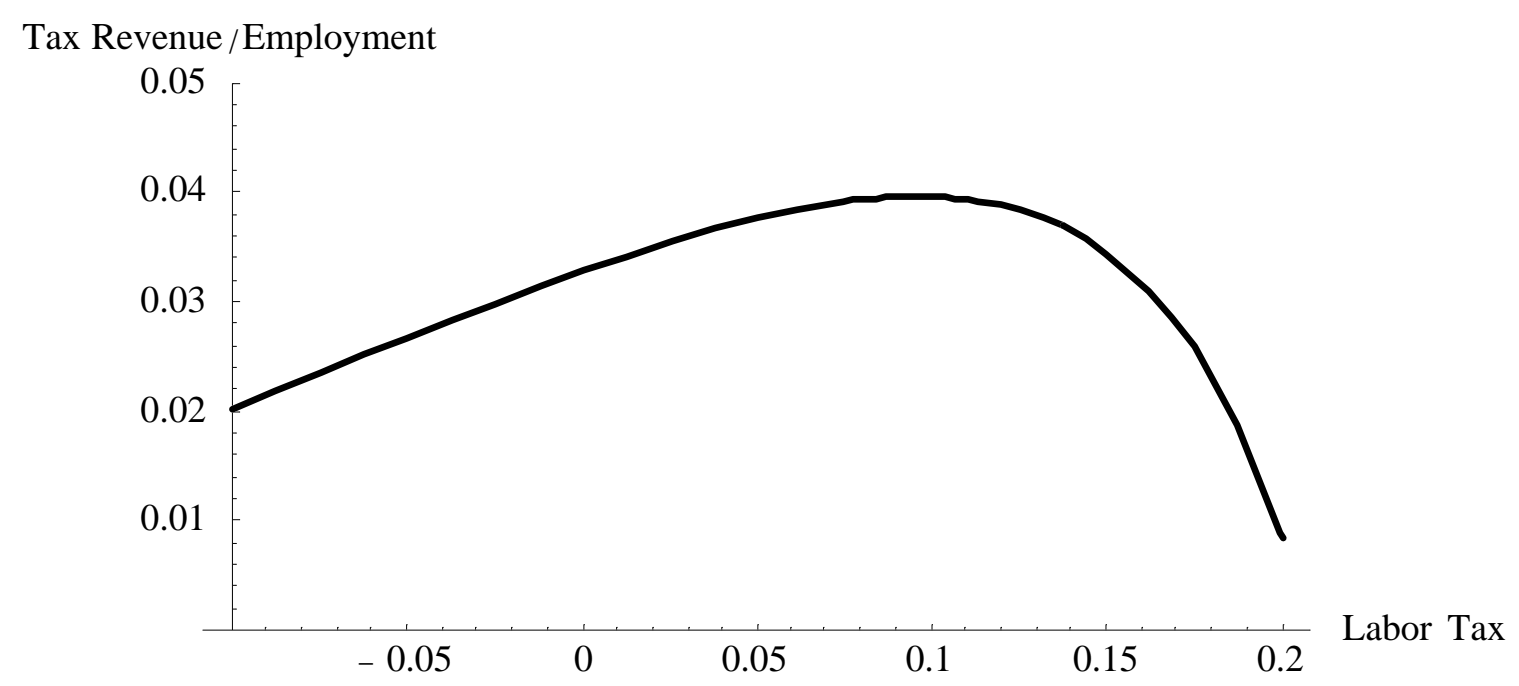

Figure 6.3: Tax Revenues Per Employed Worker

\section{Government Policy}

\subsection{National Debt Ratio}

Government policy takes the form of choosing a ratio of national debt to employment, tax rates, and unemployment benefit. ${ }^{6}$ Implications of the ratio of national debt to employment follow directly from the condition for macroeconomic equilibrium that $A S-A D$ in 3.8 equal zero or, equivalently, $3.9 .^{7}$ As a result of the conditions for macroeconomic equilibrium in balanced growth, the ratio of national debt to employment has real effects on the wage rate and on the interest rate. An increase in $D / E$ results in a smaller value of $J / E$, everything else the same. Using Theorems 3.3, 5.1 and 5.2, a smaller value of $J / E$ yields a higher value of $\theta$, a lower wage (with the qualifications in Theorem 5.2), and (for sufficiently small $b$ ) a higher interest rate. These results are summarized in the following theorem.

Theorem 7.1. Suppose that a balanced growth equilibrium holds in the Kaldor matching model with the government debt constraint holding. A higher ratio of

\footnotetext{
${ }^{6}$ See Fleck and Domenghino (1987) for consideration of the government sector in a KaldorPasinetti model.

${ }^{7}$ The ratio of national debt to employment, $D / E$, is used here instead of the empirically observed ratio of debt to aggregate output, $D /(E(p-\delta k))$. The two are proportional.
} 


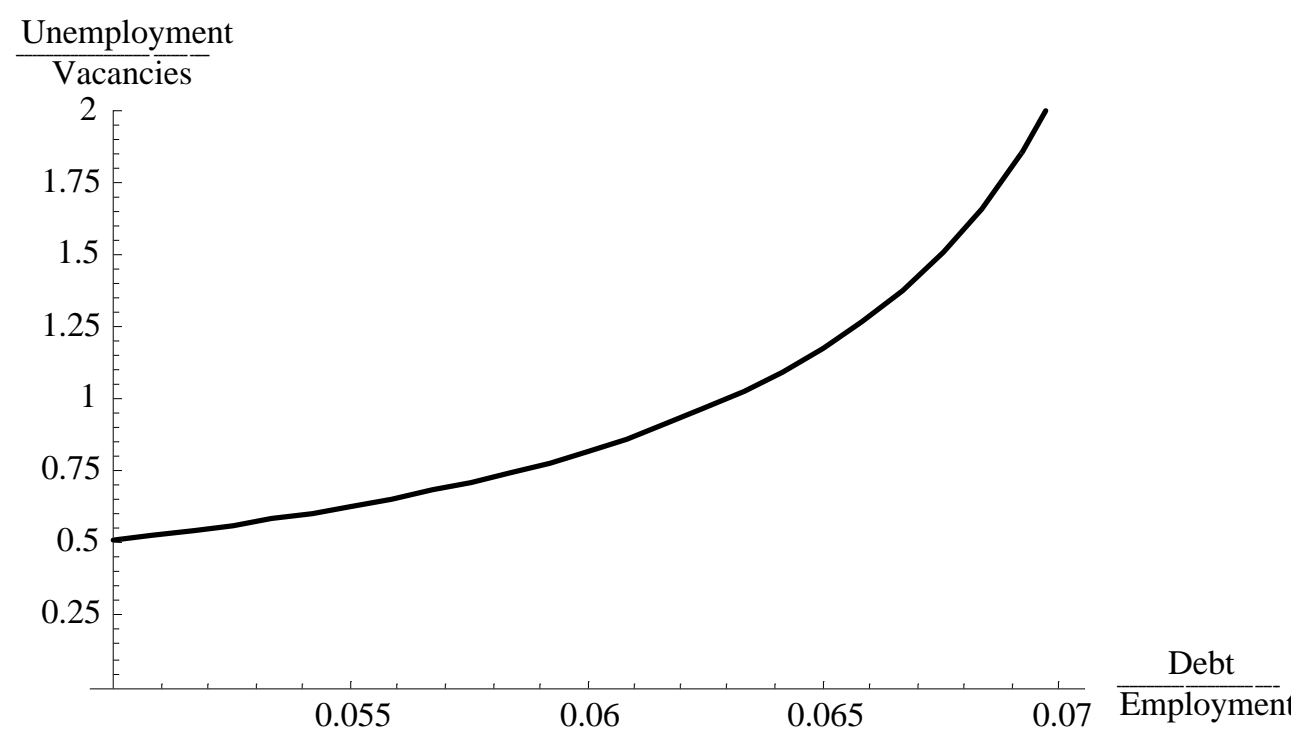

Figure 7.1: Effects of Debt to Employment Ratio on $\theta$

national debt to employment, $D / E$, yields a lower ratio of jobs to employment, $J / E$, and a higher ratio of unemployment to vacancies, $\theta$. For sufficiently small unemployment benefits, a higher ratio of national debt to employment yields a higher interest rate. It also yields a lower wage rate if $\theta$ is sufficiently near one or if $\theta$ is less than one.

As a corollary to this theorem, the unemployment rate will be higher and the vacancy rate will be lower when the ratio of national debt to employment is higher since $\theta$ is higher.

The ratio of national debt to employment has real effects on the wage and interest rate because a higher ratio absorbs savings. Then macroeconomic equilibrium occurs for a lower ratio of jobs to employment and a consequent lower need for capital investment to maintain balanced growth. The resulting higher ratio $\theta$ generates lower wages and a higher interest rate.

The theorem treats the ratio of national debt to employment as a variable exogenously determined by government policy, with transfers $R$ adjusting endogenously. As an alternative approach, one could treat $R / E$ as exogenously determined by government policy, with $D / E$ adjusting endogenously. The results are equivalent, however, since a higher level of $R / E$ will yield a higher ratio $D / E$.

Figure 7.1 illustrates the effects of the ratio of debt to employment, $D / E$, on $\theta$. This figure uses the same assumptions as Figure 2.1, along with additional assumptions affecting macroeconomic equilibrium (specifically $s=.2$ and $\rho=$ 


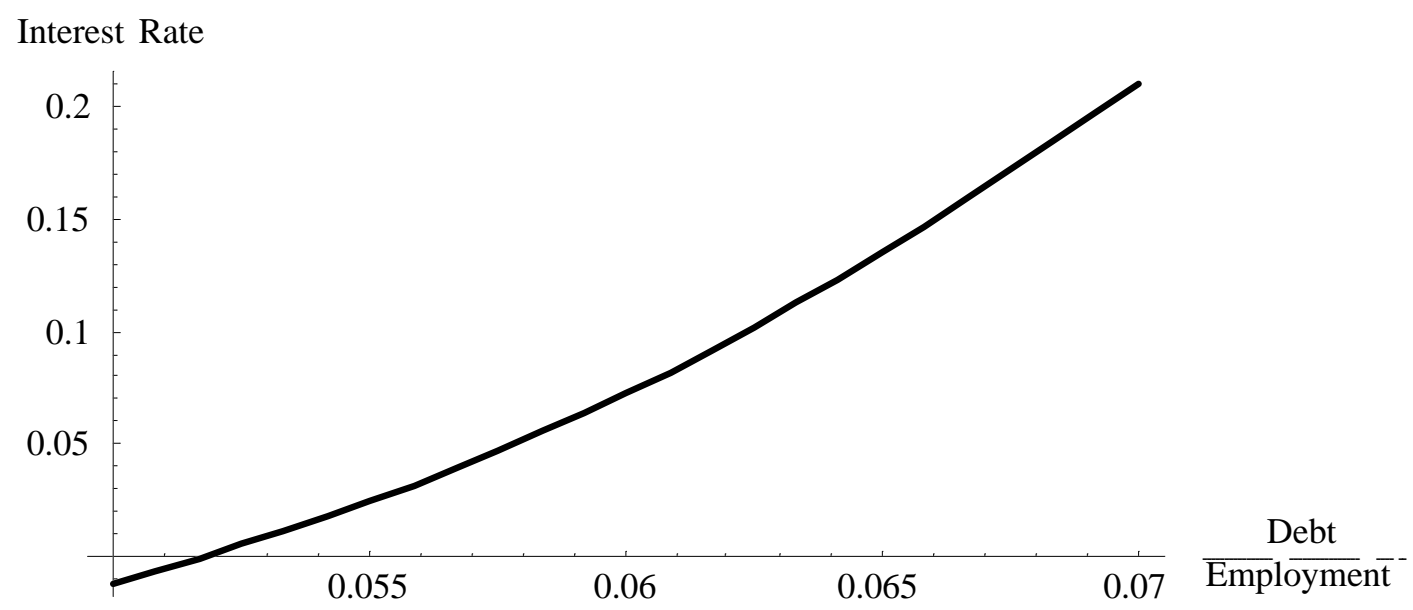

Figure 7.2: Effects of Debt to Employment Ratio on Interest Rate

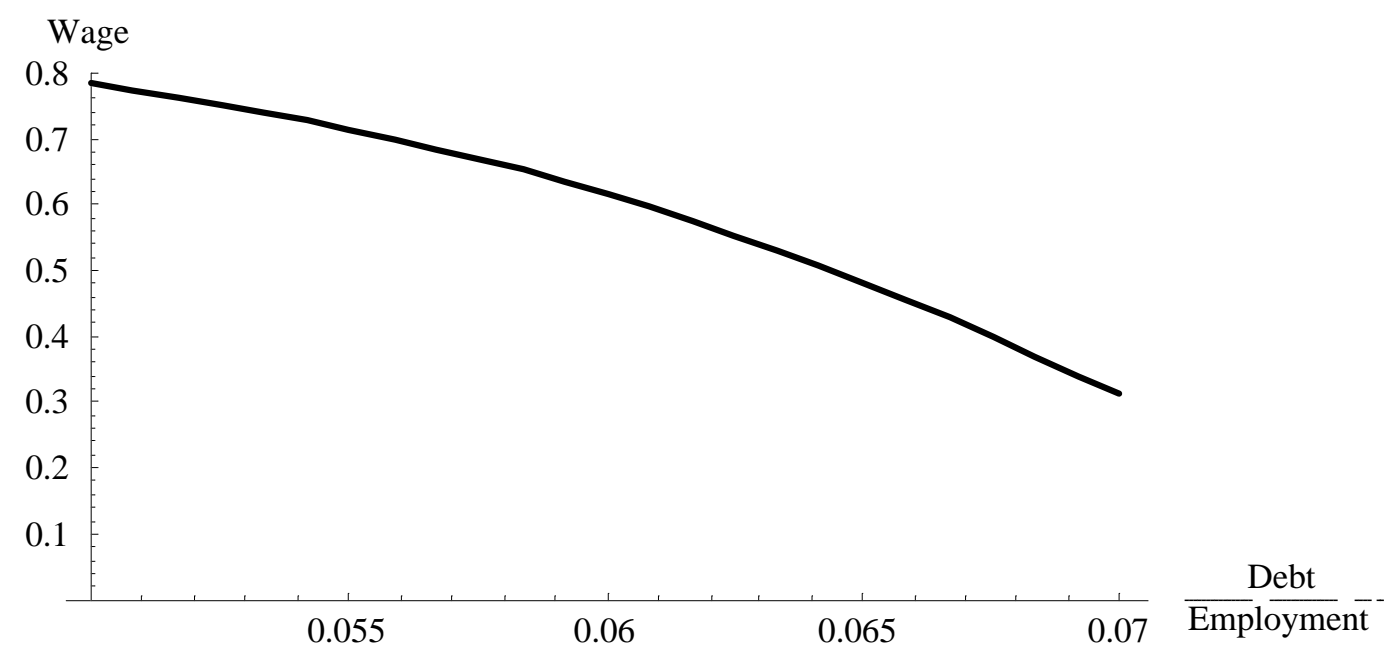

Figure 7.3: Effects of Debt to Employment Ratio on Wage Rate 
$.06)$. Figures 7.2 and 7.3 show the effects of $D / E$ on the interest rate and wage, respectively, using the same assumptions. ${ }^{8}$

\subsection{Taxes}

The tax rates $t_{w}, t_{p}$ and $t_{r}$ do not enter into the expression for macroeconomic equilibrium and therefore do not affect the ratio of jobs to employment, $J / E$, or the ratio of unemployed to vacancies, $\theta$, taking as given the ratio of national debt to employment. Also, the tax rates do not affect the relation between the wage rate and interest rate determined by the Entrepreneur Optimization Condition in 4.1. However, the tax rates do affect the relation between the wage rate and the interest rate determined by the Equilibrium Selection Condition in 2.10. This makes it relatively simple to determine the incidence of taxes on labor income and profits since only one of the two relations shifts. At a given interest rate, the relation in 2.10 shifts upward as a result of an increase in the tax rate on labor, $t_{w}$, and shifts downward as a result of an increase in the tax rate on profits, $t_{p}$. An increase in the tax rate on labor requires a higher wage so that $W_{U}$ will continue to equal $W_{V} N_{J}$, and similarly an increase in the tax rate on profits requires a lower wage rate (at each interest rate). An upward shift in the relation in 2.10 relative to the relation determined by the Entrepreneur Optimization Condition yields a higher interest rate (the two curves were shown previously in Figure 5.1). The effects on the wage rate depend on the slope of the curve from the Entrepreneur Optimization Condition, which does not shift when either $t_{w}$ or $t_{p}$ change. These results, together with Lemma 5.2, yield the following theorem.

Theorem 7.2. Suppose that a balanced growth equilibrium holds in the Kaldor matching model with the government debt constraint holding. Comparing balanced growth equilibria, an increase in the tax rate on labor income or a decrease in the tax rate on profits yield a higher interest rate. The same tax changes yield an increase in the wage if $\theta$ (the ratio of unemployment to vacancies) exceeds one; yield a decrease in the wage if $\theta$ is less than one; and yield no change in the wage if $\theta$ equals one.

If the wage rate goes up when the interest rate increases, workers are not necessarily better off in the sense that $r W_{U}$ increases. Effects on asset values will be considered in Section 8.

\footnotetext{
${ }^{8}$ In figure 7.2, the interest rate is non-positive for small ratios of $D / E$. Such balanced growth equilibria, with a non-positive interest rate, would not occur if the savings rate falls to zero when the interest rate declines to zero.
} 


\subsection{Unemployment Benefit}

The unemployment benefit $b$ affects the curves from both the Entrepreneur Optimization Condition and the Equilibrium Selection Condition. ${ }^{9}$ As a result, the effects on the interest rate will be unambiguous while the effects on the wage require qualification. From 4.1, the curve for the Entrepreneur Optimization Condition shifts up when $b$ increases. From 2.10, the curve for the Equilibrium Selection Condition shifts down when $b$ goes up (the two curves are shown in Figure 5.1). Both shifts contribute to a reduction in the interest rate. ${ }^{10}$

Since the curve for the Entrepreneur Optimization Condition may slope upward, the effects of $b$ on the wage require qualification to rule out this ambiguous case. The resulting conclusions are summarized in the following theorem.

Theorem 7.3. Suppose that a balanced growth equilibrium holds in the Kaldor matching model with the government debt constraint holding. Comparing balanced growth equilibria, a higher level of unemployment benefits yields a lower interest rate. A higher level of unemployment benefits yields a higher wage if $\theta$ is sufficiently close to one or if $\theta$ is less than one.

Figures 7.4 and 7.5 show the effects of higher values of $b$ on the interest rate and wage using the same assumptions as in Figure 2.1.

\section{Flows of Asset Values and Labor Force Participation}

This section considers the determination of the flow of asset values for workers and entrepreneurs in the economy. Analysis in previous sections has focused on effects on the wage and the interest rates. Some effects on wage rates required qualification since the net effects of changes could not be determined from shifts in curves. Even if the direction of change of the wage is known, the flows of asset values, $r W_{U}$ and $r W_{V}$, may move in contrary directions because of concurrent changes in $\theta, r$ or other variables. Determination of whether workers and entrepreneurs are better off as a result of some change therefore requires a separate analysis of the flows of asset values.

Flows of asset values are used instead of the asset values themselves because the asset values incorporate discounting of future incomes. A change that reduces the interest rate could increase the asset value through discounting while reducing the

\footnotetext{
${ }^{9}$ Optimal unemployment benefits have recently been examined by Sattinger (1995) and Fredriksson and Holmlund (2001).

${ }^{10}$ The decline in the interest rate from an increase in $b$ can also be demonstrated from 5.1, since an increase in $b$ raises $W_{U} / W_{V}$. Then the interest rate at which $W_{U} / W_{V}=N_{J}$ declines, as shown in Figure 5.2.
} 


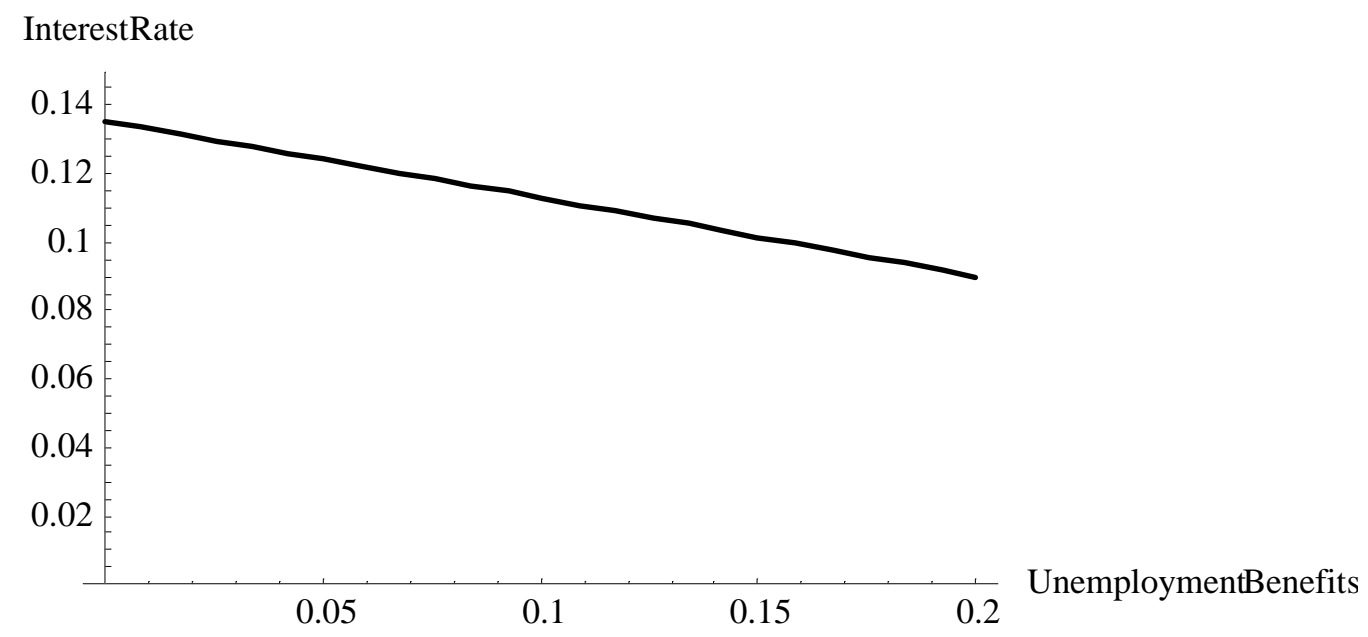

Figure 7.4: Effect of Unemployment Benefits on Interest Rate

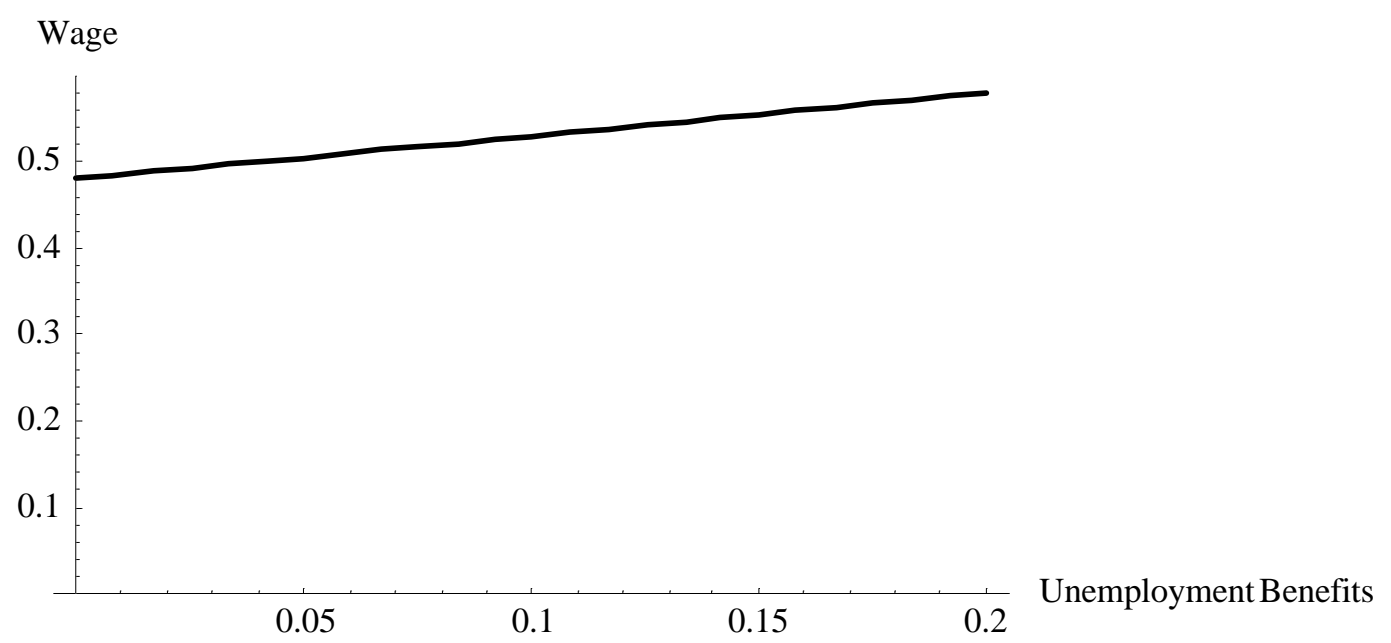

Figure 7.5: Effect of Unemployment Benefits on Wage Rate 
amount an agent receives in each period. Comparing balanced growth equilibria, an agent is unambiguously better off if the agent's flow of asset values is greater. Determination of whether workers and entrepreneurs are better off will therefore be based on comparisons of flows of asset values.

Analysis of flows of asset values is undertaken using an argument based on Figure 8.1, generated using the assumptions for Figure 2.1. The line labeled "Equilibrium Selection" shows combinations of $r W_{U}$ and $r W_{V}$ that satisfy the Equilibrium Selection Condition in 2.9. This line has slope $N_{J}$. The curve labeled " $r$ Varies, $\theta=1$ " shows combinations of $r W_{U}$ and $r W_{V}$ generated by varying the interest rate, with $\theta=1$ and the wage determined by the Entrepreneur Optimization Condition in 4.1. (The ratio $W_{U} / W_{V}$ generated by varying $r$ in this way appears in Figure 5.2 as the curve labeled " $\theta=1$ ".) The equilibrium interest rate occurs at $A_{1}$ where the curve labeled " $r$ Varies, $\theta=1$ " crosses the line labeled "Equilibrium Selection". The equilibrium when $\theta=1.4$ can be found in two steps. Holding the interest rate fixed at the equilibrium value for $\theta=1$, varying $\theta$ generates combinations of $r W_{U}$ and $r W_{V}$ that lie on the curve labeled " $\theta$ Varies". The combination for $\theta=1.4$ lies at $A_{2}$, below the curve labeled " $r$ Varies, $\theta=1$ ". This establishes that the combinations of $r W_{U}$ and $r W_{V}$ satisfying the Entrepreneur Optimization Condition shift downward. The new equilibrium will occur where the curve labeled " $r$ Varies, $\theta=1.4$ " intersects the "Equilibrium Selection" line. This occurs at $A_{3}$, at a higher interest rate and with lower values of $r W_{U}$ and $r W_{V}$. This analysis yields the following theorem.

Theorem 8.1. Suppose that a balanced growth equilibrium holds in the Kaldor matching model with the government debt constraint holding. Comparing balanced growth equilibria, a higher ratio of unemployed to vacancies (from a higher ratio of debt to employment) yields lower flows of asset values for workers and entrepreneurs.

A similar analysis can be applied to unemployment benefits, using Figure 8.2. The initial equilibrium (for $b=.12$ ) occurs at $A_{1}$ where the curve satisfying the Entrepreneur Optimization Condition (labeled " $r$ Varies, $b=.12$ ") crosses the line labeled "Equilibrium Selection". Movement to the new equilibrium occurs in two steps. With $b$ now equal to .2, but at the original interest rate, the combination of $r W_{U}$ and $r W_{V}$ is at $A_{2}$. The new equilibrium for $b=.2$ occurs where the line through $A_{2}$, labeled " $r$ Varies, $b=.2$ " intersections the "Equilibrium Selection" line at $A_{3}$. Then the interest rate is lower and $r W_{U}$ and $r W_{V}$ are both higher. This analysis establishes the following theorem.

Theorem 8.2. Suppose that a balanced growth equilibrium holds in the Kaldor matching model with the government debt constraint holding. Comparing bal- 


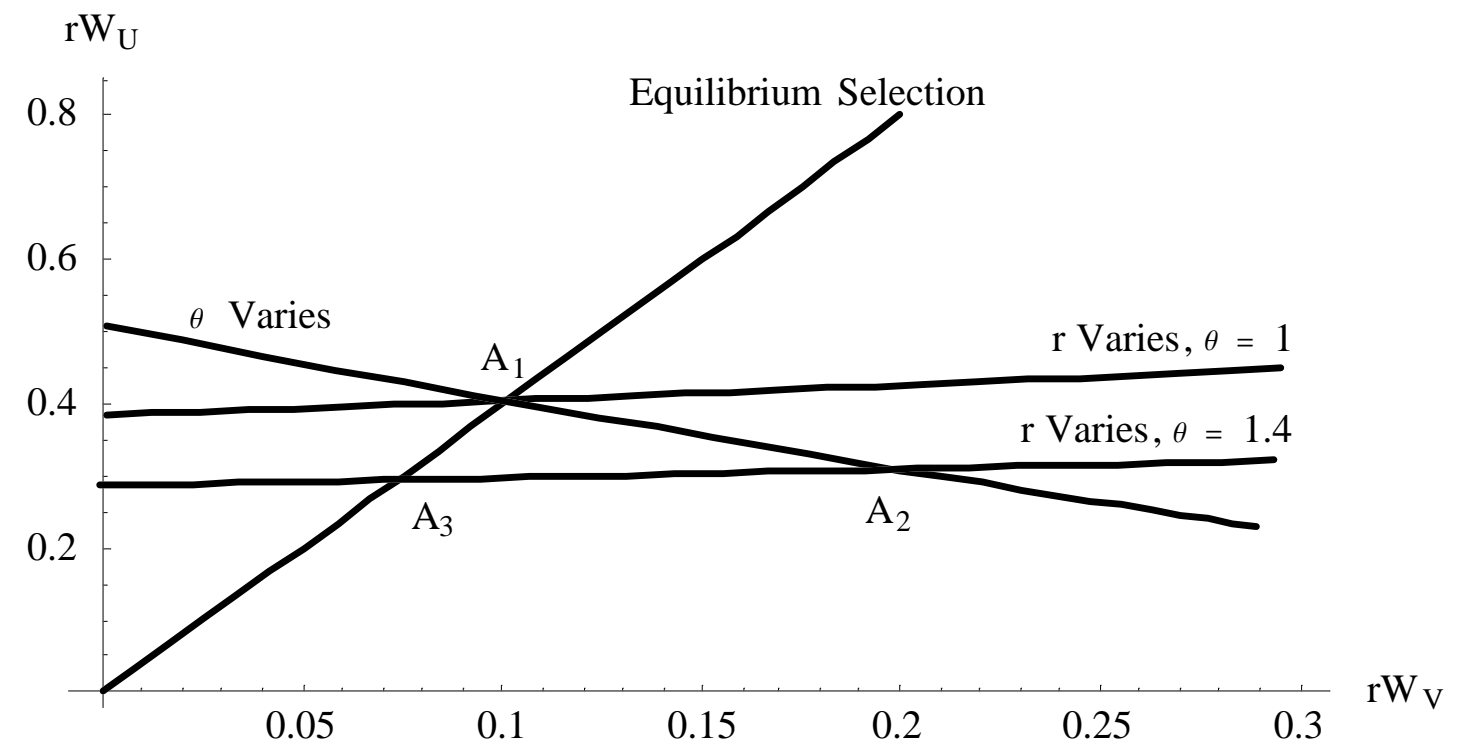

Figure 8.1: Effects of $\theta$ on Asset Values

anced growth equilibria, a higher level of unemployment benefits yields higher flows of asset values for workers and entrepreneurs.

Once the flow of asset values for unemployed workers is known, the level of labor force participation $L$ can be determined from 2.12. Then employment $E$ can be found from $L$ and $\theta$ and the balanced growth solution in 2.3. Since $L$ is an increasing function of the flow of asset value for unemployed workers, it is possible to determine the relation between the debt to employment relation, $D / E$, labor force participation $L$ and employment $E$. Figure 8.3 shows these relations using the same assumptions as Figure 2.1 (except that $\theta$ now varies) and $\rho=.02$ and $s=.2$.

\section{Extensions}

An important assumption in the original Kaldor model is that the capital to output ratio is fixed so that in the absence of a marginal product of capital, the profit share is determined at a level that yields the required savings rate. With the fixed proportion production function assumed in the Kaldor matching model, the marginal product of capital in a match is also undefined. However, in the aggregate economy, the addition of a job (requiring a fixed amount of capital) increases the balanced growth level of employment and therefore has a well-defined marginal 


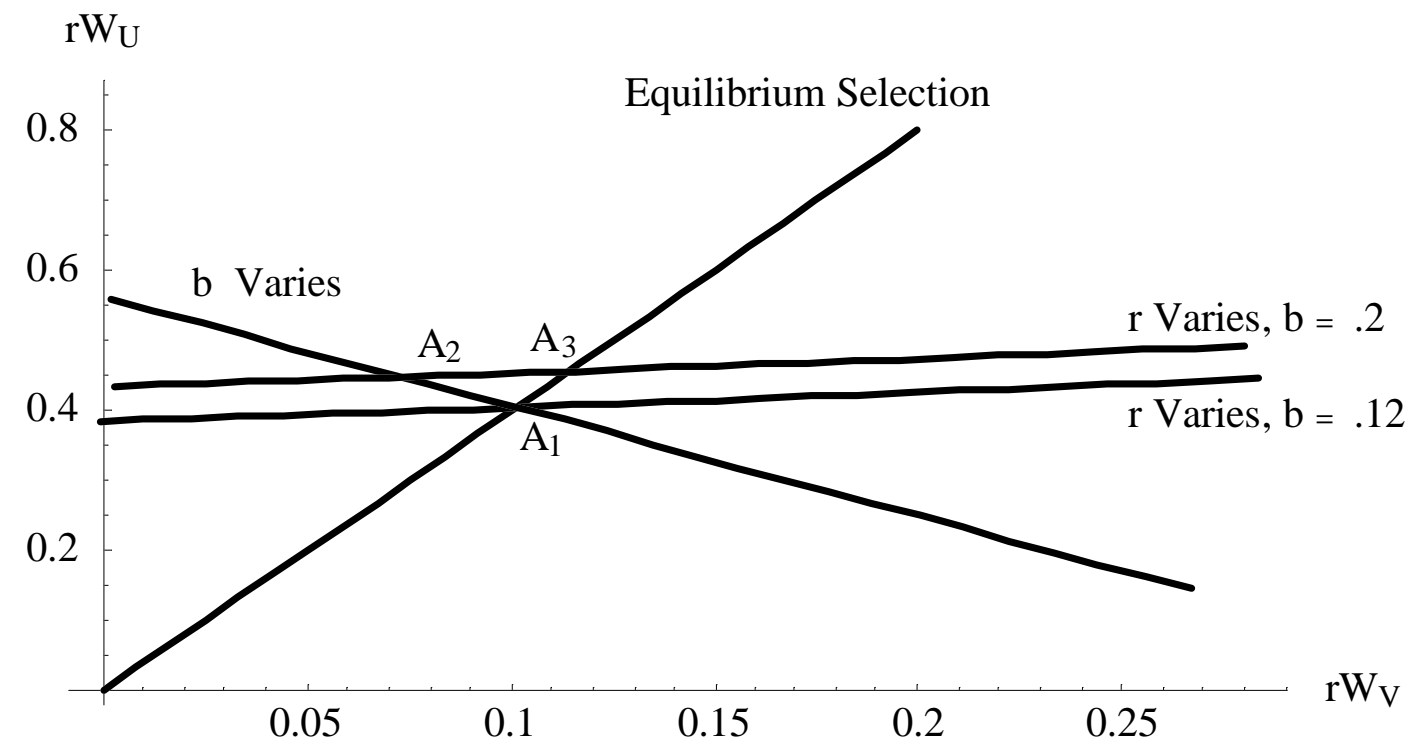

Figure 8.2: Effects of $b$ on Asset Values

Labor Force, Employment

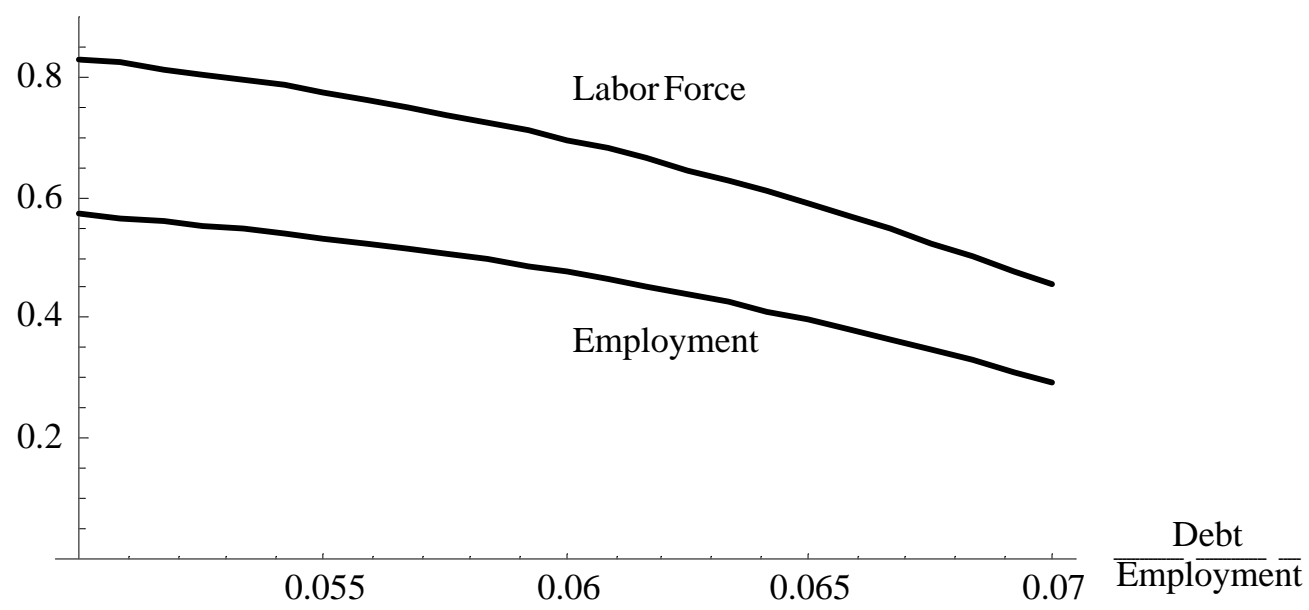

Figure 8.3: Labor Force and Employment 


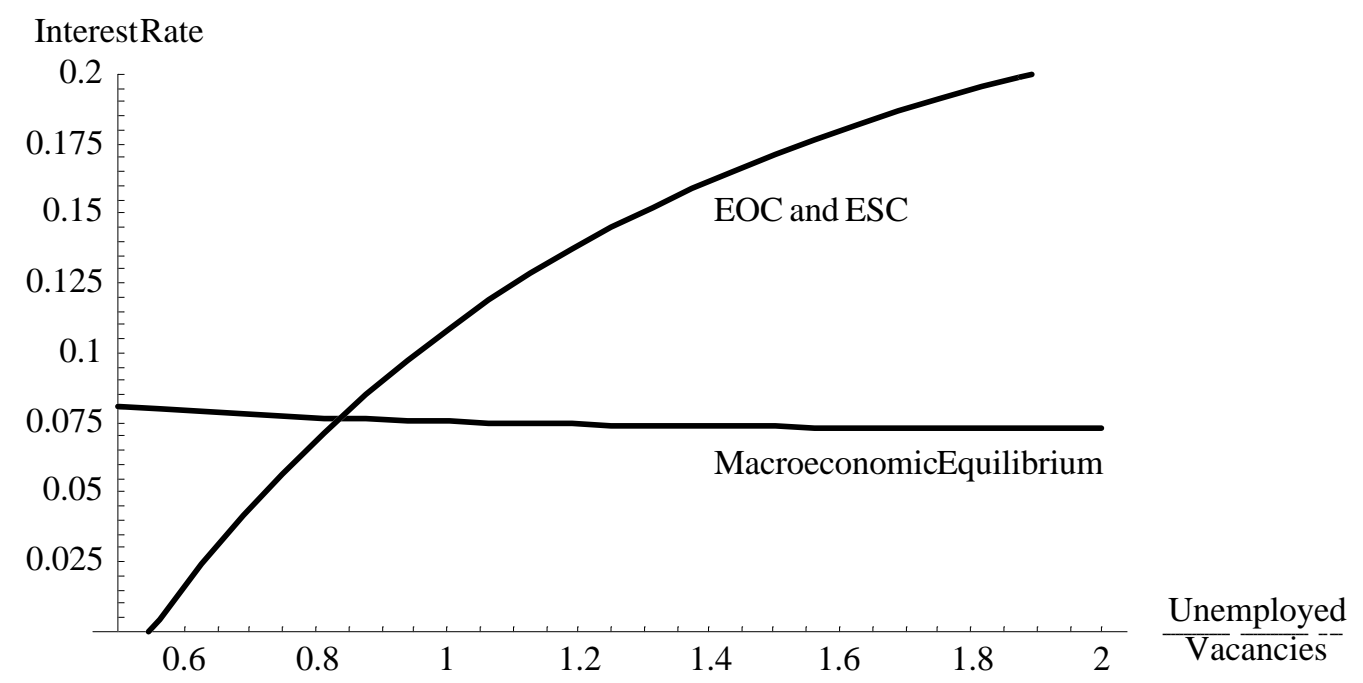

Figure 9.1: Endogenous Savings Rate

contribution to production. The use of a matching model does not have as its purpose the elimination of marginal products of factors. Instead, the matching technology is used because vacancies are well-defined (in the sense of a vacant job) and the description and determination of equilibrium arise conveniently in terms of the ratio of employed to vacancies. Using an alternative definition of vacancies, it should then be possible to assume a neoclassical production function without substantially changing basic results.

A second extension involves generalizing the savings rate to depend on the interest rate. Then macroeconomic equilibrium would determine a relation between the interest rate and the ratio of unemployed to vacancies, instead of a fixed value for the ratio of unemployed to vacancies. The Entrepreneur Optimization Condition and the Equilibrium Selection Condition determine a second relation between the two variables, $r$ and $\theta$. The second relation, together with the macroeconomic equilibrium, would then determine both $\theta$ and $r$ instead of a sequential determination. Figure 9.1 shows the relation from the macroeconomic equilibrium assuming savings are strongly affected by the interest rate, together with the relation determined by the Entrepreneur Optimization Condition and Equilibrium Selection Condition conditions. Specifically, Figure 9.1 assumes $s=r$ and the other assumptions from Figure 2.1.

With a higher ratio of debt to employment, the curve for macroeconomic equilibrium will be higher, resulting in a higher interest rate and ratio of unemployment to vacancies. This result is fundamentally the same as when $s$ is fixed, 
but involves the simultaneous solution of two equations (from the Equilibrium Selection Condition and the Entrepreneur Optimization Condition) followed by the simultaneous solution of two more equations rather than a hierarchical solution of $\theta$ first and then $w$ and $r$ from the Equilibrium Selection Condition and Entrepreneur Optimization Condition. The incidence of taxes and effects of unemployment benefits proceed by determining the shift in the relation generated by the Equilibrium Selection Condition and the Entrepreneur Optimization Condition (with the relation from macroeconomic equilibrium staying fixed), resulting in changes in $r$ and $\theta$. If, as in Kaldor's original model, savings rates for income types differ, the condition for macroeconomic equilibrium will involve the wage $w$ as well as $\theta$ and $r$, the tax rates, and unemployment benefits. This complicates the solution without changing the fundamental result that macroeconomic conditions, including the ratio of debt to employment, have real effects on the wage and interest rates.

A third extension replaces the Entrepreneur Optimization Condition with Nash Bargaining to determine the wage rate. Figure 9.2 shows the relation between the wage and interest rate determined by Nash Bargaining, together with the Equilibrium Selection Condition and the alternative relation from the Entrepreneur Optimization Condition. As shown, use of Nash Bargaining instead of the Entrepreneur Optimization Condition does not fundamentally alter the method of finding the wage and interest rate (given $\theta$ determined by macroeconomic equilibrium), but the values differ because of the location of the Nash Bargaining relation. Because Nash Bargaining does not yield equal marginal rates of substitution for entrepreneurs and workers, the conditions for efficiency are affected. Specifically, the efficient level of unemployment benefits (for efficient entry of workers) will not be zero when the tax on labor income is zero.

\section{Conclusions}

The reason for the strong conclusions of this paper, including alternative wage and interest rate combinations in balanced growth equilibrium, is the hierarchical determination of variables in equilibrium. Competitive wage setting and equilibrium selection of occupation determine the wage rate and interest rate, but only after a fundamental variable has been determined in the macroeconomic sector. Given $\theta$, the wage rate and interest rate are determined by the Entrepreneur Optimization Condition and the Equilibrium Selection Condition. However, different values of $\theta$ can be determined in macroeconomic equilibrium, with each feasible value of $\theta$ yielding a different combination of wage rate and interest rate.

In turn, the reason different values of $\theta$ are possible is that balanced growth expansion of national debt absorbs investment funds that would otherwise yield 


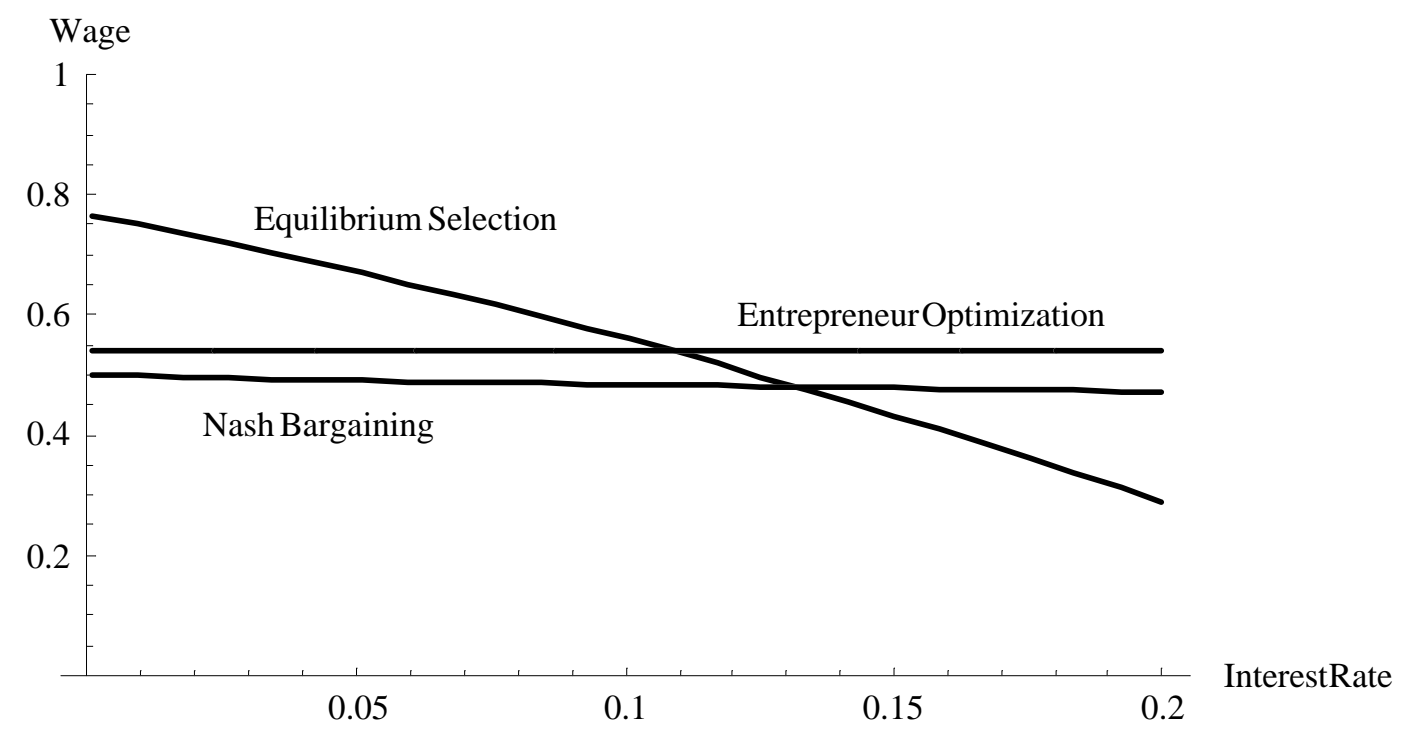

Figure 9.2: Effects of Nash Bargaining

an expansion in jobs. With a higher ratio of debt to employment, macroeconomic equilibrium occurs with a lower rate of national savings and therefore a lower rate of national investment.

The major consequence of alternative values of $\theta$ is that the wage and interest rate are not uniquely determined by competitive conditions in a balanced growth equilibrium. Instead, alternative combinations are possible depending on government policy.

The ability to carry out public finance analysis and derive conclusions arises from the structure of the model. The tax rates and unemployment benefit drop out of the condition for macroeconomic equilibrium and do not directly affect $\theta$, so that endogenous adjustments in $\theta$ do not need to be considered. Tax rates do not affect the Entrepreneur Optimization Condition so tax incidence can be carried out by looking at the shift in the Equilibrium Selection Condition. Unemployment benefits affect both the Entrepreneur Optimization Condition and Equilibrium Selection Condition but effects on the interest rate are unambiguous, while effects on wage rates require qualification. Analysis of efficient taxes and benefits is simplified because the condition on efficient selection determines the interest rate. Then the marginal product of labor for efficiency can be determined. Efficient taxes and benefits must then yield a known level of the worker asset value. A positive tax on labor income then requires a positive unemployment benefit for efficiency, and the tax on profits must then be negative to yield the predetermined 
ratio of worker to job asset values.

The Kaldor matching model explains the general patterns of the data in Table 1. When the debt to output ratio is relatively high (in the beginning and last parts of the period), the real interest rate is higher and the real wage rate is lower than in the middle period, when the debt to employment ratio is relatively low.

James Tobin $(1989$, p. 38) expressed three reservations concerning the original Kaldor model. The first concerned whether factor prices could be determined independently of their productivities. In the Kaldor matching model developed here, factor prices are not independent of their productivities, but also are not uniquely determined by them. Despite the presence of a fixed proportions production function in generating output from a match, competitive behavior of workers and entrepreneurs, reflected in the Entrepreneur Optimization Condition and the Equilibrium Selection Condition, yields a solution in which the worker asset value when unemployed equals the marginal product of labor (in the absence of taxes and unemployment benefits). In general, competitive conditions determine the wage and interest rate given $\theta$, but alternative values of $\theta$ yield non-uniqueness.. Tobin's second reservation was that the consumption function could not explain both income shares and level of output. In the Kaldor matching model, the consumption function (in the form of a constant savings rate) is combined with the Entrepreneur Optimization Condition, the Equilibrium Selection Condition, and labor supply to determine endogenously output and income distribution in balanced growth equilibrium. The consumption function is not being overburdened. Tobin's third reservation was that investment was wholly exogenous in Kaldor's original model. In the Kaldor matching model, both national savings and national investment are endogenous. National investment can vary depending on the ratio of jobs to employment. National savings can vary depending on the amount of savings absorbed by balanced growth expansion of the debt.

Previous analyses of Kaldor's original model focused on the differential savings rates, growth factors, and the absence of marginal products as the source of the results. This paper instead emphasizes the condition imposed on competitive factor price determination by macroeconomic equilibrium.

The model developed here is not quite neoclassical and not quite classical. The neoclassical content derives from the role of competitive forces in determining wage and interest rates. The departure from neoclassical models does not arise from the use of a fixed proportions production function in a match (since marginal products are defined at an aggregate level) but from the absence of uniqueness. Competitive forces determine the wage and interest rate only after determination of the particular and arbitrary ratio of unemployed to vacancies that satisfies macroeconomic equilibrium, given the ratio of debt to employment. The classical content derives from the possibility of alternative combinations of 
wages and interest rates. The departure from classical models arises because the wage and interest rate cannot be determined arbitrarily but must be consistent with competitive conditions. In method, the models also depart from classical models in the use of equilibrium conditions disapproved of by Kaldor (1972).

This paper has only explored the balanced growth part of the link between macroeconomics and income distribution, going from macroeconomic equilibria to factor prices. The short run part of the link explains how changes in income distribution bring about macroeconomic adjustment. This link is left to a later paper.

\section{References}

[1] Bertola, G. (2000), "Macroeconomics of Distribution and Growth," Chapter 9, pp. 477-540, in Anthony B. Atkinson and François Bourguignon, eds, Handbook of Income Distribution, Volume 1, Elsevier, Amsterdam.

[2] Diamond, Peter (1980), "An Alternative to Steady-State Comparisons," Economic Letters Vol. 5, pp. 7-9.

[3] (1982), "Wage Determination and Efficiency in Search Equilibrium," Review of Economic Studies, XLIX, pp. 217-227.

[4] Erosa, Andres, and Gervais, Martin (2000), "Optimal Taxation in Life-Cycle Economies," Federal Reserve Bank of Richmond Working Paper No. 00-2.

[5] Fleck, F. H. and Domenghino, C. M. (1987), "Cambridge (UK) vs. Cambridge (Mass.): A Keynesian Solution of Pasinetti's Paradox," Journal of PostKeynesian Economics Vol. 14, pp. 339-344.

[6] Fredriksson, Peter, and Holmlund, Bertil (2001), "Optimal Unemployment Insurance in Search Equilibrium," Journal of Labor Economics Vol. 19, No. 2, pp. 370-399.

[7] Ferguson, C.E. (1969), The Neoclassical Theory of Production and Distribution, Cambridge University Press, Cambridge.

[8] Hosios, Arthur J. (1990), "On the Efficiency of Matching and Related Models of Search and Unemployment," Review of Economic Studies, Vol. 57, pp. 279298.

[9] Kaldor, Nicholas (1955-1956), "Alternative Theories of Distribution," Review of Economic Studies Vol. 23, pp. 83-100. 
[10] (1972), "The Irrelevance of Equilibrium Economics," Economic Journal Vol. 82.

[11] Mortensen, Dale (1982), "Property Rights and Efficiency in Mating, Racing, and Related Games," American Economic Review Vol. 72, December, pp. 968-979.

[12] Pasinetti, Luigi L. (1962), "Rate of Profit and Income Distribution in Relation to the Rate of Economic Growth," Review of Economic Studies Vol. XXIX, no. 4, pp. 267-279.

[13] Phelps, Edmund (1972), Inflation Policy and Unemployment Theory: The Cost-Benefit Approach to Monetary Planning, MacMillan, London.

[14] Pissarides, Christopher (1984), "Efficient Job Rejection," Economic Journal Vol. 94, pp. 97-108.

[15] (2000), Equilibrium Unemployment Theory, second edition, MIT Press, Cambridge.

[16] Rothschild, Kurt W. (1993), Employment, Wages and Income Distribution, Routledge, London.

[17] Sattinger, Michael (1985), Unemployment, Choice and Inequality, SpringerVerlag, Berlin.

[18] (1990), "Unemployment, the Market for Interviews, and Wage Determination," Journal of Political Economy, Vol. 98, No. 2, pp. 356-371.

[19] (1995), "General Equilibrium Effects of Unemployment Compensation with Labor Force Participation," Journal of Labor Economics Vol. 13, No. 4, pp. 623-652.

[20] (2001), Income Distribution Volume I, Edward Elgar, Cheltenham.

[21] Skott, Peter (1989), Kaldor's Growth and Distribution Theory, Peter Lang Verlag, Berlin.

[22] Tobin, James (1972), "Inflation and Unemployment," American Economic Review Vol. 62, pp. 1-18.

[23] (1989), "Growth and Distribution: A Neoclassical KaldorRobinson Exercise," Cambridge Journal of Economics Vol. 13, pp. 37-45. 
[24] Weintraub, Sidney (1958), An Approach to the Theory of Income Distribution, Chilton Company, Philadelphia.

[25] Yashiv, Eran (2000), "The Determinants of Equilibrium Unemployment," American Economic Review Vol. 90, No. 5, pp. 1297-1322. 


\section{IZA Discussion Papers}

\begin{tabular}{|c|c|c|c|c|}
\hline No. & Author(s) & Title & Area & Date \\
\hline 366 & M. C. Regets & $\begin{array}{l}\text { Research and Policy Issues in High-Skilled } \\
\text { International Migration: A Perspective with Data } \\
\text { from the United States }\end{array}$ & $1 / 5$ & 09/01 \\
\hline 367 & C. Dustmann & $\begin{array}{l}\text { Parental Background, Primary to Secondary } \\
\text { School Transitions, and Wages }\end{array}$ & 5 & 09/01 \\
\hline 368 & J. Angrist & $\begin{array}{l}\text { How Do Sex Ratios Affect Marriage and Labor } \\
\text { Markets? Evidence from America's Second } \\
\text { Generation }\end{array}$ & 5 & 09/01 \\
\hline 369 & A. S. Kalwij & $\begin{array}{l}\text { Individuals' Unemployment Durations over the } \\
\text { Business Cycle }\end{array}$ & 3 & 09/01 \\
\hline 370 & A. S. Kalwij & $\begin{array}{l}\text { Individuals' Unemployment Experiences: } \\
\text { Heterogeneity and Business Cycle Effects }\end{array}$ & 3 & 09/01 \\
\hline 371 & $\begin{array}{l}\text { S. C. Wolter } \\
\text { A. Zbinden }\end{array}$ & $\begin{array}{l}\text { Rates of Return to Education: The View of } \\
\text { Students in Switzerland }\end{array}$ & 5 & 09/01 \\
\hline 372 & $\begin{array}{l}\text { J. Konings } \\
\text { H. Lehmann }\end{array}$ & $\begin{array}{l}\text { Marshall and Labour Demand in Russia: Going } \\
\text { Back to Basics }\end{array}$ & 4 & 09/01 \\
\hline 373 & S. J. Trejo & $\begin{array}{l}\text { Does the Statutory Overtime Premium } \\
\text { Discourage Long Workweeks? }\end{array}$ & 1 & $10 / 01$ \\
\hline 374 & $\begin{array}{l}\text { G. J. van den Berg } \\
\text { B. van der Klaauw }\end{array}$ & $\begin{array}{l}\text { Counseling and Monitoring of Unemployed } \\
\text { Workers: Theory and Evidence from a } \\
\text { Controlled Social Experiment }\end{array}$ & 6 & $10 / 01$ \\
\hline 375 & $\begin{array}{l}\text { J. A. Dunlevy } \\
\text { W. K. Hutchinson }\end{array}$ & $\begin{array}{l}\text { The Pro-Trade Effect of Immigration on } \\
\text { American Exports During the Late Nineteenth } \\
\text { and Early Twentieth Centuries }\end{array}$ & 1 & $10 / 01$ \\
\hline 376 & G. Corneo & Work and Television & 5 & $10 / 01$ \\
\hline 377 & S. J. Trejo & $\begin{array}{l}\text { Intergenerational Progress of Mexican-Origin } \\
\text { Workers in the U.S. Labor Market }\end{array}$ & 1 & $10 / 01$ \\
\hline 378 & $\begin{array}{l}\text { D. Clark } \\
\text { R. Fahr }\end{array}$ & $\begin{array}{l}\text { The Promise of Workplace Training for Non- } \\
\text { College-Bound Youth: Theory and Evidence } \\
\text { from German Apprenticeship }\end{array}$ & 1 & $10 / 01$ \\
\hline 379 & $\begin{array}{l}\text { H. Antecol } \\
\text { D. A. Cobb-Clark }\end{array}$ & $\begin{array}{l}\text { The Sexual Harassment of Female Active-Duty } \\
\text { Personnel: Effects on Job Satisfaction and } \\
\text { Intentions to Remain in the Military }\end{array}$ & 5 & $10 / 01$ \\
\hline 380 & M. Sattinger & $\begin{array}{l}\text { A Kaldor Matching Model of Real Wage } \\
\text { Declines }\end{array}$ & 7 & $10 / 01$ \\
\hline
\end{tabular}

